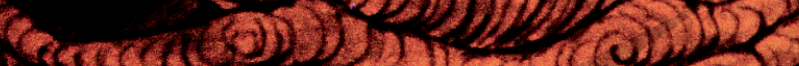

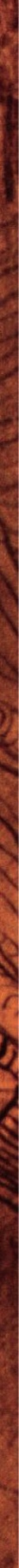

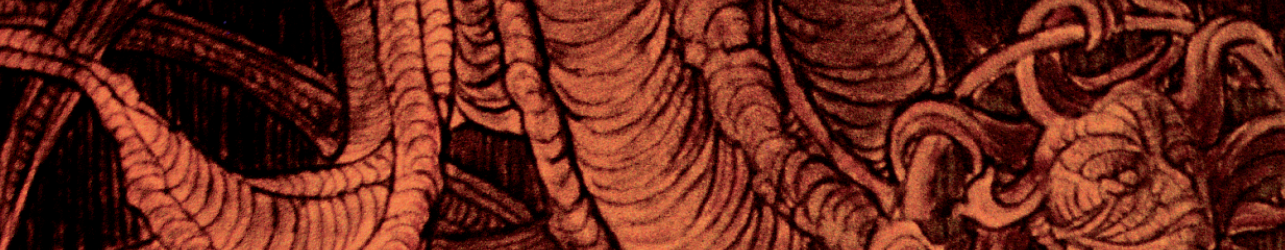




\title{
Trasfondo trágico en la pintura de Luis Ortega Bru
}

\author{
Tragic Undertones in Paintings by Luis Ortega Bru
}

\author{
Andrés Luque Teruel \\ Universidad de Sevilla, España \\ luquete@us.es
}

http://orcid.org/0000-0003-3807-9239

Recepción: 24/02/2020 |Aceptación: 24/04/2020

\section{Resumen}

El artículo plantea el reflejo del sufrimiento de Luis Ortega Bru en su pintura como consecuencia de los trágicos sucesos que vivió en la guerra civil española. A ese sufrimiento se ha aludido en numerosas ocasiones; sin embargo, apenas se ha tenido en cuenta a la hora de estudiar su escultura, muy conocida, en buena medida porque quedaba oculto bajo el dolor pasionista en sus temas religiosos, los únicos que se habian estudiado hasta hace muy poco. Mucho menos su pintura, que no se ha dado a conocer de modo sistemático hasta un reciente estudio, con la lógica carencia para la fijación de su personalidad artística desde una perspectiva global hasta ese momento, en la que quedaron claras sus aportaciones en uno u otro género y las relaciones establecidas entre ambos. Por ello, es el momento de profundizar en el trasfondo trágico que las caracteriza.

\section{Abstract}

This article focuses on the reflection of Luis Ortega Bru's suffering in his paintings, as a result of the tragic events he experienced during the Spanish Civil War. His distress has been mentioned on many occasions; however, it has gone unnoticed in the study of his well-known sculptural work, hidden behind renderings of passionate sorrow in his religious art (the only part of his body of work that has been studied until recently). With the exception of a recent publication, his paintings have not been studied in a systematic way. As a result, his artistic career has not been analyzed from a global perspective, including his contributions to both genres as well as the relationships between them. Thus, it is time to delve deeper into their tragic undertone.

\section{Palabras clave}

Pintura

Realismo

Expresionismo

Vanguardias

Ortega Bru

Guerra Civil

\section{Keywords}

Painting

Realism

Expressionism

Avant-Garde

Ortega Bru

Civil War 
Es de sobra conocida la dureza de los acontecimientos que marcaron la juventud de Luis Ortega Bru en la guerra civil española del año 1936, lo que no se ha tenido en cuenta es la repercusión que esos hechos dramáticos tuvieron en su vida y su personalidad artística, y, como consecuencia de ello, cómo se reflejaron en su pintura, producción esta que no ha sido estudiada de modo sistemático ni parcialmente hasta una iniciativa muy reciente 1 , y no aparece en ninguno de los estudios panorámicos efectuados hasta este momento sobre la pintura sevillana posterior a 1950², aún cuando varios autores importantes han planteado cuestiones como "practicar arte hoy, hacer pintura hoy y un presente imposible"3.

La conciencia de esta proyección artística, avalada por el testimonio personal de su hermana Marina, ha permitido comprobar cómo esa problemática derivada de lo vivido y sufrido con el alzamiento antirrepublicano y en la guerra, fluye en su pintura de modo intenso y dramático, quizás porque esta no gozó de la difusión de su producción escultórica y, por lo tanto, no estuvo expuesta a la consideración de nadie. En sus esculturas, ese sentimiento latente quedó oculto bajo la entidad de la temática principal, el sufrimiento de Cristo, lo suficientemente dramático en sí mismo como para asumir la mayor parte de la carga de sentido sin que nadie pudiese denunciar en ello la proyección personal de su propio padecimiento ${ }^{4}$. Sí pudo hacerlo en esas pinturas cuyos temas eligió con libertad y permanecieron en un ámbito íntimo; sin embargo, no fue fácil hacerlo eludiendo las responsabilidades políticas que el régimen hubiera podido aplicar con la contundencia represiva conocida ${ }^{5}$. Los hermanos Ortega Bru ya habían sufrido demasiado como para exponerlos de modo inconsciente.

Luis Ortega Bru expresó el drama y su sentimiento desgarrado en claves simbólicas que pasan desapercibidas a simple vista bajo la apariencia de un tema ajeno a los hechos, y, al mismo tiempo, se pueden descifrar con cierta facilidad siguiendo la dinámica de determinadas claves intelectivas, dispuestas como pistas para una correcta

1. Andrés Luque Teruel, Luis Ortega Bru. Vanguardia inédita (Sevilla: Tartessos, 2011), 158-165, 225-228, 228-230, 236-248, 272-279, 299312 , y $348-351$.

2. Ana Guasch, 40 años de pintura en Sevilla (1940-1980)(Sevilla: Obra Cultural de la Caja de Ahorros Provincial San Fernando, 1981), 9-13.

3. Fernando Martín Martín, "Notas sobre la creación contemporánea en Sevilla," en Pintura de Sevilla, 1952-1992 (Sevilla: Comisaría de la ciudad de Sevilla para 1992 y Monte de Piedad y Caja de Ahorros de Huelva y Sevilla, 1992), LII; Fernando Martín Martín, "Pintura contemporánea en Sevilla," en Sevilla y su provincia, (Sevilla: Gever, 1993), 5: 363-404; José Antonio Chacón Álvarez, Las rutas del Arte Contemporáneo en Andalucía (Sevilla: Fundación José Manuel Lara, 2011), 11.

4. Manuel Tobaja Villegas, "Luis Ortega Bru," en El Arte en la Semana Santa. Artistas en el recuerdo (Sevilla: Caja Provincial San Fernando, 1986), s/n; Rafael Ríos Delgado, "El escultor Ortega Bru y la Hermandad de la Bofetá," Boletín de las Cofradías de Sevilla, no. 521 (2002): 38-39; Rafael Ríos Delgado, "El artista Juan Pérez Calvo," Boletín de las Cofradías de Sevilla, no. 539 (2004): 38-43; Carmen García Rossell, "Luis Ortega Bru," en De Jerusalén a Sevilla, La Pasión de Jesús(Sevilla: Editorial Tartessos, 2005), 4: 60.

5. Ian Gibson, Vida, pasión y muerte de Federico García Lorca (Madrid: Plaza y Janet, 1998; Barcelona: Ediciones Folio-ABC, 2003), 17-30. 
interpretación, y, sobre todo, en función de los contenidos expresivos que los superan y les proporcionan su verdadero sentido.

\section{Una revisión necesaria de los hechos para determinar las claves simbólicas de su pintura}

La preocupación, el sufrimiento extremo y la desolación están presentes en las pinturas de Luis Ortega Bru desde sus primeros dibujos en 1935 hasta su fallecimiento en 1982. Por ello, es imprescindible tener en cuenta sus circunstancias personales en los años trágicos de la década de los treinta del siglo XX. No se trata aquí de volver con ánimo revisionista ni menos revanchista a unos hechos complejos que ya han tratado con la distancia y el rigor debidos acreditados historiadores, sino de dilucidar la angustia vital y el alcance de los padecimientos psíquicos que pudieron afectar de modo determinante al artista, señalando las causas de estos.

Luis Ortega Bru nació el día 10 de septiembre de 1916 en la barriada de la Estación de San Roque ${ }^{6}$. Era hijo y nieto de alfareros y el mayor de siete hermanos: Marina, Germinal, Augusto, Onésimo, Áurea, y Eliseo, este fallecido en 1927 con solo cinco meses de $v i_{a}{ }^{7}$. La elección de esos nombres indica un posicionamiento en consonancia con las ideas masónicas. Sus vínculos familiares eran muy fuertes, y su gusto infantil y juvenil por el modelado del barro, facilitado en el alfar familiar en el que había trabajado su abuelo, Juan Ortega Valenzuela, y lo hacía su padre, Ángel Ortega López, los refuerzan. Este había nacido en 1888, por lo que solo se llevaban veintiocho años de diferencia.

Menos aún con su madre, Carmen Bru Casado, que había nacido en Cartagena en 1892. Ella atendía la tienda de cerámica en la que se vendían los productos del alfar familiar y además ejercía de partera de la localidad, actividad esta en la que se había formado a la antigua usanza, esto es, de modo práctico y sin titulación. Era una mujer culta, circunstancia nada común en las clases medias de aquella época, situación debida a su procedencia de la familia del marqués de Comillas, de la que había quedado apartada debido a su pensamiento librepensador y su carácter independiente.

6. Benito Rodríguez Gatius, Ortega Bru (Sevilla: Guadalquivir, 1995), 11-15; Benito Rodríguez Gatius, "Semblanza sobre la figura del escultor Luis Ortega Bru," Boletín de las Cofradías de Sevilla, no. 526 (2002): 49.

7. Antonio Pérez Girón, El San Roque de Luis Ortega Bru (San Roque: Delegación Municipal de Cultura, 2016), 9-21. 
El matrimonio formado por Ángel Ortega López y Carmen Bru Casado, y el primer hijo de ambos, Luis Ortega Bru, eran personas de izquierdas muy comprometidas políticamente en tiempos de la Segunda República. Ella tuvo participación activa en el acto del centenario de los liberales fusilados en el municipio, celebrado en el cementerio de San Roque en junio de 1931. Él fue masón y sindicalista, actividad esta que ejerció como presidente de la CNT, y lo llevó a presidir también el Ateneo Cultural Obrero de San Roque y el Partido Sindicalista fundado por Ángel Pestaña. Su firma consta en calidad de presidente del mismo en la solicitud de este último para un mitin en el teatro Salón Alameda en mayo de 1935, en el que también intervino Carmen Bru. En definitiva, ambos fueron muy activos políticamente durante la República.

Después de pasar por diversos profesores de dibujo locales en sus años infantiles, en la escuela del maestro Gabriel Arenas y en la academia de dibujo de los hermanos Juan y José Domingo de Mena, el joven Luis Ortega Bru había iniciado su formación como escultor en la Escuela de Artes y Oficios de La Línea de la Concepción, en la que estuvo matriculado desde 1931. Pronto se vinculó a las Juventudes Libertarias. El Ayuntamiento de San Roque le encargó uno de sus primeros trabajos como escultor, el Monumento a la Segunda República8, en 1935, destruido en 1936.

En ese mismo año de 1936, las fuerzas nacionales tomaron San Roque el día 18 de julio. Marina Ortega Bru es una fuente directa por la que sabemos cómo vivió la familia aquellos días, la intranquilidad por la que estaban pasando en su entorno y las reacciones ante los acontecimientos de sus padres y hermano mayor ${ }^{9}$. Por ella sabemos que Ángel Ortega López y Luis Ortega Bru participaron en una reunión con el objetivo de apoyar a una columna republicana que pretendía restablecer el orden constitucional en la localidad tomando los cuarteles de infantería y la guardia civil. Esa misma mañana, los dos interrumpieron la celebración de una misa con un propósito no aclarado del todo, pues mientras algunas fuentes aluden a que esta encubría una reunión pro fascista ${ }^{10}$; otras afirman que lo hicieron para advertir a los ciudadanos de la inminente llegada de las fuerzas republicanas y el consiguiente enfrentamiento armado. Padre e hijo estuvieron presentes en esas acciones y los dos se vieron forzados a abandonar su casa con la entrada de nuevas fuerzas marroquíes al servicio del bando nacional procedentes de Algeciras, que tomaron definitivamente la plaza.

8. Pérez Girón, 16 y 130.

9. Marina Ortega Bru y Antonio Pérez Girón, Memorias. Luis Ortega Bru (San Roque: Fundación Municipal de San Roque, 2002), 23-24.

10. Ortega Bru y Pérez Girón, 21-23. 
Carmen Bru estuvo todo el día atendiendo a los heridos de ambos bandos que entraban en el Hospital Municipal, pues debido a su experiencia sanitaria consideró que debía prestar ayuda a todo aquél que lo necesitase. Antonio Pérez Girón advirtió sobre la angustia que debió vivir pensando en que en cualquier momento podía entrar malherido o muerto su esposo o su hijo Luis ${ }^{11}$. Como vimos, Carmen Bru fue una ciudadana activa en política durante la Segunda República; sin embargo, no participó de ningún modo en las acciones militares del día 18 de julio, o mejor dicho, deberíamos resaltar pese al riesgo de caer en la reiteración, que solo lo hizo como sanitaria y de modo solidario, pues entendió que esa era su obligación moral como ciudadana.

No llegó a ver a su marido ni a su hijo, que se trasladaron a zona republicana por razones de seguridad y para seguir apoyando al gobierno legalmente constituido. Pasadas décadas, Marina Ortega Bru aún recuerda con amargura cómo Ángel Ortega solo pudo despedirse de Carmen Bru a través de una carta que le entregó a ella misma. Luis Ortega Bru sirvió a la República con lealtad en los frentes de Málaga, Almería y Elche, donde una ráfaga de metralla le reventó un oído, motivo por el que fue trasladado a Madrid y, debido a que sabía escribir, destinado a la Sección Cartográfica de El Pardo, donde intervino en la elaboración de mapas en relieve de Madrid, con el objetivo de ayudar al ejercito republicano a impedir la entrada de Franco en la ciudad.

Carmen Bru no dejó de atender heridos durante los días siguientes y fue detenida sin haber participado en los hechos bélicos el día 4 de agosto de 1936. Se encontraba en su domicilio de la calle General Lacy y fue interrogada en el cuartel Diego Salinas, de donde fue trasladada a la cárcel de Algeciras. Marina contó emocionada cómo su madre escoltada por dos guardias civiles le entregó a su pequeña hermana Áurea y el dinero que llevaba encima. Ninguna institución ni persona física presentó cargos contra ella, y tampoco hubo juicio que la condenase por motivo alguno; simplemente, fue trasladada al término municipal de Tarifa y asesinada a sangre fría junto a otras tres mujeres por su pasado republicano y la participación activa de su marido y su hijo Luis en la defensa del orden constitucional legal.

Los niños quedaron solos en casa hasta que llegó su abuela paterna y los llevó a su casa de la calle Larga, en la que también vivían su tía Mariquita y su marido Eduardo. Pasadas

11. Pérez Girón, El San Roque, 10-11. 
seis décadas, Marina Ortega Bru cuenta con inmensa pena cómo siendo solo unos niños indefensos fueron abandonados por sus familiares más cercanos, pues incluso su tía Mariquita y el marido eran contrarios a su presencia allíin. En buena parte por miedo a las represalias, temor que los llevó a reprocharle que su padre tenía las manos manchadas de sangre. Marina no podía creérselo y fue a hablar con los abogados José García Sánchez y Andrés Vázquez de Sola, que le dijeron que eso no era cierto, sino al contrario, que su madre había salvado muchas vidas aquellos días y su padre evitó que fusilaran al segundo ${ }^{13}$. Según ella, la pequeña Áurea sintió tanto dolor con la ausencia y la muerte de su madre que perdió las ganas de vivir, falleciendo con solo catorce años.

Los primeros días, Marina y sus hermanos abrieron la tienda de cerámica, pese a que el alfar fue asaltado y apenas le quedaban productos que vender. Tuvieron que hacer un enorme esfuerzo para sobrevivir cuando aún estaban en edad escolar. Augusto trabajó fregando en un bar; Onésimo se fue al campo con unos tíos a cuidar pavos y cerdos; Germinal se fue a vivir con un hermano de su madre; María se dedicó a coser y lavar ropa a los militares; y la pequeña Áurea fue expulsada del colegio porque las madres no querían que su hija compartiese clase con "la hija de una roja"14. En sentido contrario, explicó cómo algunos vecinos los ayudaban por la noche y fingían no hablarles ni interesarse por ellos a la luz del día; y todavía recuerda agradecida, cómo Basilia, la esposa de Andrés Vázquez de Sola, tuvo el detalle de llevarles unos regalos el día de Reyes.

Ángel Ortega López y su hijo Luis Ortega Bru volvieron a San Roque una vez finalizada la guerra, debido a la promesa de Franco de no tomar represalias con los republicanos que no habían cometido actos violentos. Cometieron un grave error, sobre todo el primero, pues fueron detenidos en la misma estación por haber participado en el asalto a los cuarteles el día 18 de julio. El padre fue condenado a pena de muerte por el delito de rebelión militar; el hijo a tres años de cárcel por auxilio a la rebelión militar, y entró en el batallón de Trabajadores, establecido en la calle Málaga.

Detenido Ángel Ortega López tuvo que pasar por otro duro trance, su hijo Onésimo falleció atropellado por un coche en extrañas circunstancias cuando se dirigía a la estación en bicicleta en agosto de 1939. Preso en aquel momento no pudo velar el

12. Ortega Bru y Pérez Girón, Memorias, 27.

13. Ortega Bru y Pérez Girón, 28.

14. Ortega Bru y Pérez Girón, 27-29. 
cadáver ni asistir a su entierro ${ }^{15}$; su hija Marina aportó el testimonio de prisioneros que pasaron aquel día con él, y por ellos sabemos que, desesperado, se dio repetidos golpes contra la pared ${ }^{16}$. El relato de Marina sobre su desenlace es estremecedor, cuando llegó a casa se encontró a su hermano Luis Ilorando sin consuelo, y este solo le preguntó: “¿ya? Ella le contestó afirmativamente y entonces él la abrazó y le dijo"17: "No llores, algún día nos vengaremos, pero nuestra venganza no será con tiros ni contra nadie". Marina no entendió la respuesta, hasta que con el tiempo vio la obra de Luis Ortega Bru en el Museo Municipal de San Roque y comprendió que allí estaba su venganza ${ }^{18}$.

Pasados unos días de la muerte de Ángel Ortega López detuvieron a su hijo Luis Ortega Bru, que quedó en libertad provisional en 1940 y libre en 1943. Convertido en un escultor de gran éxito en las décadas de los cincuenta, sesenta y setenta del siglo XX, en las entrevistas que le hicieron siempre eludió hablar de estos hechos y de cualquier sentimiento en relación con ellos en su arte. Se escudó siempre en una retórica compleja, con la que contuvo o en la que escondió sus sentimientos. Cualquiera que lo escuchase podía darse cuenta cuánto había podido sufrir aquel hombre y cómo se enrocaba por miedo; aunque sus más allegados no tienen ningún reparo en reconocer que en privado sí censuraba lo que había pasado y mostraba su repulsa a los responsables.

Su personalidad se forjó, de ese modo, condicionada por los acontecimientos. Es curioso que en esas entrevistas, Luis Ortega Bru tampoco comentara nada sobre los conceptos, las formas ni los estilos de sus esculturas ${ }^{19}$. Su discurso quedaba a medio camino entre lo mucho que subyacía bajo esta y la necesidad de expresarlo sin desvelar que en realidad el grito desgarrado y el sufrimiento que surgían de las esculturas era el suyo propio, su rebeldía ante lo inevitable y para siempre, ante la pérdida de todo menos de la dignidad que siempre mantuvo.

\footnotetext{
15. Pérez Girón, El San Roque,12.

16. Ortega Bru y Pérez Girón, Memorias, 32-33.

17. Ortega Bru y Pérez Girón, 33.

18. Benito Rodríguez Gatius, "Desafiando a la vida con el Arte," en Luis Ortega Bru. Un genio en solitario, ed. Andrés Luque Teruel (Sevilla: Tartessos, 2011), 26.

19. Andrés Luque Teruel, "Personalidad artística. Etapas y estilos," en Luque Teruel, Luis Ortega Bru, 56.
} 


\section{Los primeros dibujos, antes de la Guerra Civil y sus consecuencias en la familia}

Los hijos de Luis Ortega Bru fechan tres dibujos suyos cerca de 1935, antes de los terribles sucesos comentados ${ }^{20}$. Son tres retratos naturalistas, que sirven para indicarnos cómo fue su primera aproximación a la representación en el plano.

Según Benito Rodríguez Gatius, en uno de ellos representó a su madre, Carmen Bru ${ }^{21}$; sin embargo, Alberto Parra Sevilla lo registró en los inventarios familiares con la doble posibilidad de identificarla con aquélla o con la hija de esta, su hermana Marina Ortega $\mathrm{Bru}^{22}$, por este motivo quedó catalogada como Retrato de Carmen Bru o Retrato de Marina Ortega Brü23. Es un retrato correcto y con tendencia al natural, caracterizado por el trazo sobrio y bien definido y una clara contención formal y expresiva. La seriedad del rostro y un cierto aire melancólico concuerdan con los retratos fotográficos generalizados por aquella época. Como es lógico dada la cronología anterior a los sucesos de julio de 1936, no muestra ningún rasgo expresionista ni los caracteres expresivos tan introspectivos que pudiéramos deducir de dibujos y pinturas posteriores.

La intensidad de la mirada como correlato de los retratos fotográficos es aún mayor en el Retrato de Germinal Ortega Bru ${ }^{24}$, del mismo año o muy cercano; y aún mucho más en Autorretrato ${ }^{25}$. En este último dibujo optó por un doble movimiento del que carecen los anteriores, por una parte desde la perspectiva física con el decidido giro del cuello; de modo alternativo, con la proyección virtual de la mirada, con la que inició un nuevo planteamiento conceptual.

En los tres casos, los criterios técnicos son análogos y la definición anatómica correcta. Luis Ortega Bru aún no había iniciado su actividad como pintor y mostró una sólida formación en el dibujo, corroborada por el hábil manejo de las luces y las sombras para el desarrollo de los volúmenes. La eficacia de las gradaciones compensa la rígida pose

20. Luis Ángel Ortega León, Débora Ortega León, y Carmen Ortega León, Proyecto Luis Ortega Bru, Inédito. Para número de catálogo de obras, a partir de ahora: Luis Ángel, Débora y Carmen Ortega León, AOL. Alberto Parra Sevilla, APS. Benito Rodríguez Gatius, BRG. Andrés Luque Teruel, ALT.

21. Rodríguez Gatius, Ortega Bru, 23.

22. Rodríguez Gatius, 23; Alberto Parra Sevilla, "Obra inédita de Luis Ortega Bru” (trabajo de investigación, Universidad de Sevilla, 2002); Andrés Luque Teruel, "Actualidad de un amplio Catálogo," en Luque Teruel, Luis Ortega, 257-401.

23. Colección Carmen Ortega León. Lápiz y pastel sobre papel grueso, 15,5 ×11,5 cm. BRG 3; APS 2, 36; ALT 1.

24. Colección Carmen Ortega León. Lápiz y pastel sobre papel grueso, 15,5 × 11,5 cm. BRG 3; APS 2, 36; ALT 2.

25. Colección Carmen Ortega León. Lápiz y pastel sobre papel grueso, 15,5 × 11,5 cm. BRG 3; APS 2, 36; ALT 3 . 
en los dos primeros, limitados por esto en cuestiones expresivas; y potencia los recursos del tercero, cuyo movimiento es indicativo de un incipiente interés por la interacción de las fuerzas internas.

\section{El poder simbólico del dibujo sustituye a la expresión explícita de la palabra, en 1936-1949}

Durante los tres años que estuvo recluido en el penal de El Puerto de Santa María, en 1936-1939, Luis Ortega Bru intentó mantenerse activo con los escasos medios a su alcance, y es seguro que allí modeló un Crucificado para darle culto, pues dada su condición de creyente, manifestada desde niño cuando decidió tomar la primera comunión a petición propia, le aportaría el consuelo necesario en las duras circunstancias del penal. También allí realizó el dibujo titulado, Molina de Segura ${ }^{26}$, firmado y fechado en 1937. En ese dibujo representó a una joven sentada, ligera de ropa y en actitud propia del mundo del espectáculo. El pantalón muy corto y excesivamente ajustado y el sujetador con tirantes de volantes lo confirman. El movimiento de la cabeza y el brazo izquierdo hacia un mismo lado y acariciando el pelo asumen un matiz erótico característico en las poses femeninas de la época. En cuestiones técnicas, el joven artista muestra una nueva orientación hacia un dibujo lineal, con una gran seguridad en la definición de las líneas de contorno, y el complemento de sombras y gradaciones suaves. La volumetría es contundente, tanto como el cuerpo de mujer que representa, aunque las terminaciones de la cara y las cuatro extremidades apenas están abocetadas u ocultas, carácter determinante en sus relieves sevillanos del primer lustro de los años cincuenta.

Benito Rodríguez Gatius citó otros dibujos femeninos de esta época que no se conservan ${ }^{27}$, que, como este de Molina de Segura, pudieran interpretarse como una evasión mental, un recuerdo agradable o el deseo de un hombre joven en momentos difíciles de reclusión. En definitiva, en cierto modo reflejarían esa carencia en la realidad de la prisión y la dureza extrema de la posguerra con la privación de la libertad, el hambre y el miedo a un juicio y una situación sin garantías.

26. ALT 9.

27. BRG 2 y 3 ; ALT 11 y 12. 
En esa misma época o recién salido del penal de El Puerto de Santa María, a inicios de 1940, realizó los dibujos Niño llorando ${ }^{28}$ y La muerte de un adolescente ${ }^{29}$. Los dos están por identificar; sin embargo, los temas representados son muy significativos, el primero porque el dramatismo del tema elegido concuerda con la cronología y las circunstancias de sus hermanos cuando vieron cómo detuvieron y supieron que habían asesinado a su madre, y cuando se repitió el drama con la detención y la condena a muerte de su padre ${ }^{30}$; el segundo porque el tema coincide con la dramática muerte de su hermano Onésimo, muerto en supuesto accidente en 1939. De los títulos de esos dos dibujos se deduce que Luis Ortega Bru dejó así constancia de los hechos, de la realidad física de sus hermanos. Fue un modo personal de recordarlo, de fijar esos acontecimientos mediante imágenes que quedasen para siempre, al menos en su entorno íntimo.

Las penalidades y el miedo que pasaría en esas circunstancias serían muy considerables. La evasión mental, imprescindible para la superación de tal angustia, encontraría una salida en el dibujo y con esa práctica retomó, ahora con otros propósitos y posibilidades, el camino del arte. Pudo verse en la primera exposición individual celebrada en el Centro de Educación y Descanso de San Roque, en 1943.

El reflejo de esas penalidades comenzó a mostrarse con toda su intensidad en el dibujo Desnudo con caballo y perro ${ }^{31}$, cerca de 1943. Es una obra clave en la evolución de Luis Ortega Bru. La composición itinerante muestra un desnudo masculino montado a caballo, seguido por un perro. El tema en sí mismo no tiene porqué tener ningún condicionante asociado, la carga de sentido está implícita en el desarrollo formal, pues las líneas decididas y firmes definen los contornos descendentes de cada figura, de manera que prefiguran el cansancio extremo, la extenuación del jinete y los dos animales. Todos marchan abatidos, vencidos física y moralmente. Las sombras acentúan los contrastes expresivos en ese sentido itinerante. La simplificación anatómica es ejemplar y proporcional a la definición lineal, y la estilización está en consonancia con las expresiones graves, agotadas. La composición presenta una gran contradicción entre la vitalidad de las relaciones internas del medio plástico y la falta de vida de los protagonistas, desvanecidos como su familia y buena parte de la sociedad española de la época.

\footnotetext{
28. BRG 3; ALT 15.

29. BRG 3; ALT 16.

30. Luque Teruel, Luis Ortega Bru. Vanguardia, 23-26.

31. Herederos de las hermanas de Ortega Bru. ALT 18.
} 
Luis Ortega Bru anticipó con ese dibujo los conceptos fundamentales de la escultura que modeló en los años siguientes, a medio camino entre el realismo y el expresionismo y con fluctuaciones constantes entre ambos. No puede decirse que sea un dibujo expresionista en un sentido pleno o en la acepción internacional del término; mas sí que está muy cerca de ese estilo por cuanto incentiva la exageración y deformación de las formas con un interés expresivo prioritario. Aquí están presentes aspectos del lenguaje propio que le dio tanta fama, pues las líneas tienen una capacidad de definición innata y además asumen una función expresiva equivalente a la de los cortes visibles y las aristas en las esculturas. Hubiese sido previsible una transposición de esos caracteres en ambos sentidos; sin embargo, esta no se produjo y su producción escultórica y la pictórica siguieron pautas distintas después de un período de inactividad entre este dibujo y sus primeras pinturas, ya en la década de los años cincuenta.

\section{El reconocimiento de la angustia interior: La piedra filosofal, en 1960}

El lustro comprendido entre 1955 y 1960 fue fundamental para la consagración de Luis Ortega Bru como escultor en Madrid. En esos años acabó de definir su estilo tan peculiar, oscilante entre el realismo y el expresionismo, e inició una tendencia abstracta e informalista que tuvo un desarrollo correlativo en una serie de dibujos y pinturas ${ }^{32}$, fechados cerca de 1960, con los que puso fin a un período equivalente de inactividad como pintor.

La serie dedicada a La piedra filosofal dejó muy claras dos cuestiones, sus nuevos intereses plásticos por los caminos de las vanguardias; y los planteamientos simbólicos que le permitieron encauzar una carga de sentido intencionada. En La Piedra Filosofal 133, dibujo con lápiz sobre papel, planteó un bloque cúbico y hermético, con dos cortes en la superficie frontal en forma de cruz. En La Piedra Filosofal $11^{34}$ representó un volumen parecido, en este caso idéntico al de mayor tamaño de los dos que componen las dos versiones del grupo escultórico con el mismo título, resuelto con colores puros y brillantes. Aquí puede verse lo que ya se intuía en el primer dibujo y es evidente en los grupos escultóricos, el bloque informal queda suspendido en un nivel superior, como el

32. Andrés Luque Teruel, "La relación con las vanguardias como modo de expresión," en Ortega Bru. Centenario (1916-2016), ed. Javier González Torres (Málaga: Archicofradía Sacramental de Pasión y Ars Málaga-Palacio Episcopal, 2016), 53-63; Juan Antonio Sánchez López, “Citius, altius, fortius. Deporte, dinamismo, cuerpo," en González Torres, Ortega Bru. Centenario, 65-80.

33. Colección Carmen Ortega León. Lápiz sobre papel. APS 2, 51; ALT 144.

34. Colección Carmen Ortega León. Témpera sobre cartulina marrón. APS 3, 32; ALT 145. 


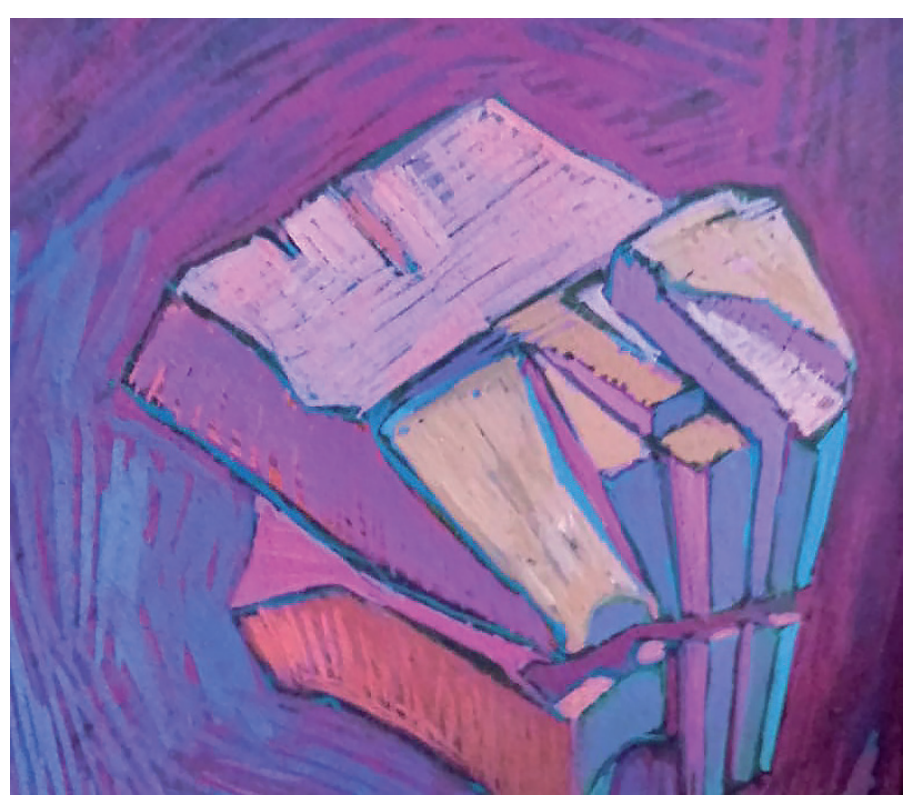

Fig. 1. Luis Ortega Bru, Piedra filosofal, 1960.

pensamiento y la facultad de pensar. En la pintura tiene una fuerte presencia la sombra, conseguida con un color azul intenso, que actúa como contrapunto de dicha facultad.

Las relaciones internas de La piedra filosofal II presentan el volumen informal con aplicaciones expresionistas sobre un hábil aprovechamiento de recursos racionales procedentes de otras tendencias vanguardistas, lo que determina una naturaleza artística autónoma respecto de las dos versiones de la escultura. Como es el caso de La piedra filosofal II/35, en la que los tonos celestes sobre el rojizo del bloque y los trazos del mismo color sobre el negro del soporte representan la incidencia del aire y el movimiento. El espacio también presenta variantes en La Piedra Filosofal IV ${ }^{36}$, en la que el bloque tiene colores arbitrarios y queda suspendido en un lugar indeterminado. La que tiene características distintas es La Piedra Filosofal $V^{37}$, cuyo volumen disperso y un tanto expandido ha perdido la condición de bloque. Desde un punto de vista plástico, esto la distancia del informalismo y la introduce en el expresionismo y las abstracciones con planos someros; y en lo que concierne al espacio, introduce una nueva sensación aérea desde un punto de vista superior.

Luis Ortega Bru no dijo en ningún momento qué era para él la piedra filosofal, qué quiso representar. Si se buscan significados asociados debemos tener en cuenta que su primera acepción es la que le dio la alquimia como aspiración a una sustancia ideal capaz de convertir los metales en oro o plata. No parece que eso pudiera interesarle mucho al artista, y menos cuando presentó un bloque pétreo y no una sustancia; cuando definió una realidad hermética y no una materia capaz de transformarse. Las otras dos acepciones son mucho más acordes con la necesidad del artista de expresar sus sentimientos, su modo de pensar ${ }^{38}$. Se refieren a la piedra filosofal como elixir de la vida eterna, como medio para alcanzar la inmortalidad; $y$, como consecuencia de esta, a una perfección superior o estado de iluminación y felicidad celestial.

35. Colección Carmen Ortega León. Témpera sobre cartulina negra. APS 3, 31; ALT 146.

36. Colección Carmen Ortega León. Témpera sobre cartulina negra sobre tabla de contrachapado. APS 3, 29; ALT 147.

37. Colección Carmen Ortega León. APS 3, 33; ALT 148. 
Teniéndolos en cuenta podemos interpretar los dos grupos escultóricos, los dibujos y las pinturas en un sentido simbólico superior, que explica el interés del artista por el tema, su reiteración en el mismo. Inmortal es el recuerdo de los seres queridos, nadie desaparece del todo mientras alguien lo recuerda ${ }^{39}$. Luis Ortega Bru pudo estar recordando así a sus padres y hermanos, de ese modo abstracto, sin una forma reconocible concreta, como un estado interior que se manifiesta en la rotundidad del bloque como definición eterna. Por ese motivo, no debe extrañarnos que cada grupo escultórico fuese una pequeña instalación con dos bloques consecutivos y descendentes, cada uno tallado en un material distinto, madera y yeso, que podrían representar la unión de Ángel Ortega López y Carmen Bru, esto es, el vuelo eterno y la presencia constante de sus padres.

El único dibujo o pintura que no respondería a ese significado simbólico sería la quinta, sin la condición de bloque de las demás y compatible con la transformación de la sustancia de la primera acepción, que tampoco tendría una correspondencia directa con las esculturas. Puede ser una simple variante formal del tema representado, una especie de prueba alternativa a la que no habría que buscar una carga de sentido distinta; aunque también pudiera ser un primer intento de representar el hecho que condujo a esa nueva realidad inmaterial volcada en el símbolo de la piedra filosofal.

La que sí se relaciona desde un punto de vista formal es El juguete ${ }^{40}$, que no es parte de la serie, y presenta un objeto informal en primer plano análogo al bloque de La Piedra Filosofal II, de la que, por otra parte, se desmarca con el fondo movido, ondulante y con efecto centrípeto, con el que entra en tensión. Las relaciones plásticas pudieran de nuevo aportar una información valiosa para su interpretación, pues ese fondo con pinceladas yuxtapuestas y nerviosas no solo alivia la contundencia volumétrica y la perfecta definición del objeto, también y sobre todo refleja un estado de inquietud en la relación. Teniendo en cuenta los parecidos formales razonables y el hecho concreto de que no representa ningún juguete u objeto reconocible, cabe preguntarse si no sería demasiada aventurada la posibilidad de que ese juguete fuese la identidad oculta en la piedra filosofal, o lo que es lo mismo, el destino de sus padres en manos de otros, de ahí el choque visual entre el objeto y su contexto, entre el bloque y el fondo que se expande y lo repele. Eso la pondría en relación con el posible significado de La piedra filosofal $\mathrm{V}$.

39. Hans-Georg Gadamer, La actualidad de lo bello (Barcelona: Ediciones Paidós, 1977), 29-65.

40. Colección Carmen Ortega León. Técnica mixta, témpera y tinta negra sobre cartón. APS 3, 30; ALT 149. 
Siempre ha llamado la atención la modernidad formal de estas pinturas de Luis Ortega Bru, y nunca nadie ha reparado en sus posibles significados, y eso que los títulos aportan una información valiosa para interpretarlos. Muchas veces se han considerado excentricidades abstractas, más o menos geniales, o exabruptos expresionistas de un creador impulsivo, a las que no se les ha querido dar un sentido concreto más allá de sus valores plásticos, quizás porque el hermetismo con el que se desenvolvió el artista fue una parte importante en el valor de los contenidos, muy presentes y bien ocultados a la vez en tiempos de censura y represión de la libertad de expresión.

Eso hace difícil la interpretación de otras pinturas igual de herméticas, sobre cuyas cargas de sentido aún no tenemos indicios suficientes para interpretar, como La Ca-

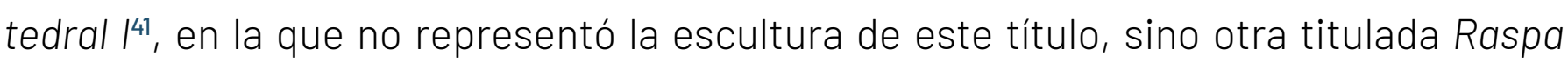
pescado y una variante de la talla Óseo I a escala. Los dibujos abstractos agrupados en varias hojas y fechados entre 1960 y 1965 son estudios diversos, con planteamientos y soluciones que no tienen nada que ver entre sí.

\section{Dolor y rabia contenidos: las pinturas fantásticas, en 1960-1965}

Las pinturas fantásticas de Luis Ortega Bru, denominadas así siguiendo el término propuesto por Walter Schurian ${ }^{42}$, son una serie de técnicas mixtas con representaciones de temas derivados o asociados a la mitología griega y a la psicología y los estados de ánimo del ser humano, resueltas con una intervención decisiva de la línea y caracterizadas por los movimientos continuos de estas con la consiguiente tendencia a la transformación de los temas figurativos. Todas están fechadas entre 1960 y 1965 y permanecieron inéditas durante décadas.

Ese "arte fantástico" lo es en tanto que representa las preocupaciones del ser humano, los temores y las angustias que padece, reales o soñadas, y con estas fundamenta una inventiva personal y apasionada, en la que es posible la integración de distintos recursos plásticos, en este caso vanguardistas y expresionistas, en una misma configuración o proyecto. Según lo expuesto, y en la medida que representan realidades intangibles, son pinturas reales, tanto como los conceptos a los que alude en la realidad física del ser

41. Colección Carmen Ortega León. Témpera sobre cartulina negra, 22,5 × $25 \mathrm{~cm}$. APS 3, 10; ALT 178.

42. Walter Schurian, Arte Fantástico (Madrid: Taschen y Diario El País), 9 y 10. 


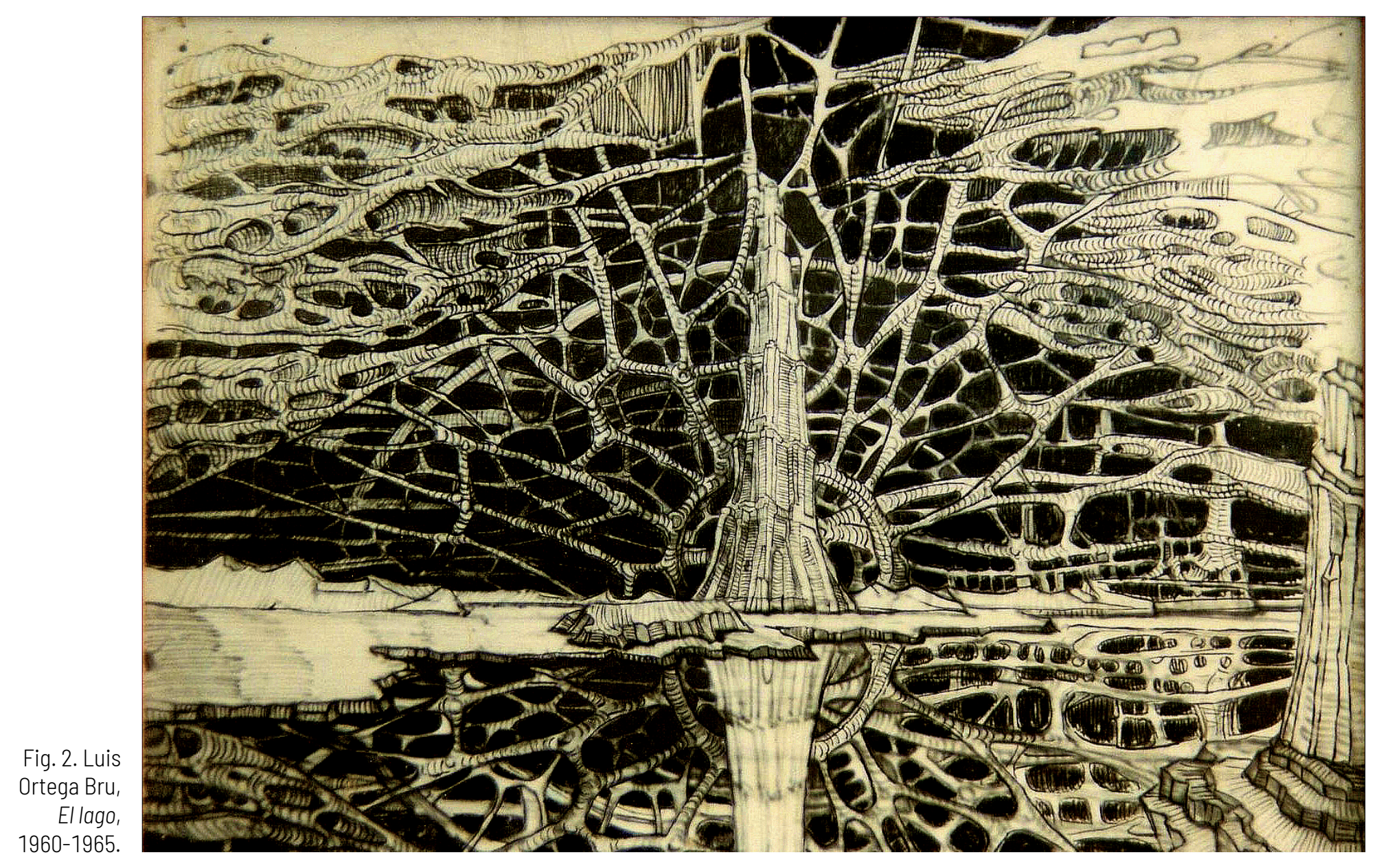

humano y la vida diaria ${ }^{43}$. Aquí se manifiestan como consecuencia de la reflexión personal y la proyección de esas reflexiones en el subconsciente artístico.

Esa correlación puede verse en todas y desde el principio. En La Catedral $11^{44}$, fechada cerca de 1960 representó la escultura con el mismo título ante un paisaje irreal que se refleja en la base indefinida ${ }^{45}$. Ya dijimos de la primera versión que el significado simbólico de ese supuesto edificio, en realidad una estructura orgánica sin condición de uso como entidad tectónica, es por ahora difícil de identificar. Sí podemos hacerlo con el fondo, cerrado por una pantalla en forma de segmento de círculo calado que anticipa la configuración de la escultura El Eco46, en 1965; y el volumen único de la pintura De lo material del $\mathrm{ECO}^{47}$, cerca de 1965. La aparente indefinición del espacio simbólico y la uniformidad tonal simulan y desvelan la escena en la misma medida, proporcionándole un aspecto irreal. En los dos elementos optó por la abstracción orgánica de las formas

43. Luque Teruel, Luis Ortega Bru. Vanguardia, 236-248.

44. Colección de los herederos de Ortega Bru. Témpera y tinta negra sobre tabla, $305 \times 57$ cm. BRG 85, Lám. 144; APS 3, $22 ;$ ALT 177. 
elegidas, la catedral casi espectral; el segmento de círculo que pudiera relacionarse con las ondas sonoras del eco a modo de rueda. El significado de este sí parece claro ${ }^{48}$, el eco es la voz que se repite y permanece en la consciencia; es el relato de lo que pasó y no podía olvidar; es el recuerdo permanente que lo afligía y le provocaba una tremenda angustia; es la rabia contenida de quien le prometió a su hermana Marina una venganza sin violencia física; es la conciencia clara de que él y los suyos eran mejores personas que los asesinos que acabaron con la vida de su madre y los militares que condenaron a muerte a su padre ${ }^{49}$.

Luis Ortega Bru utilizó un doble lenguaje muy frecuente en distintos círculos literarios y periodísticos más independientes de aquel momento. La duplicidad de los volúmenes solapados e invertidos a través de un elemento reflectante plantea un juego visual que tiene correspondencia en la carga de sentido de El lago ${ }^{50}$. El agua devuelve la imagen de un tejido abstracto y orgánico precedido de otro informal vertical, de cuyo ángulo inferior izquierdo asoma otro volumen abstracto, este racional y con apariencia constructiva. Los volúmenes irregulares y asimétricos están trabajados en negativo y la tinta negra del fondo libera contrasiluetas. Leámoslo del siguiente modo, el agua es la metáfora de la vida misma, en la que se refleja la realidad y permite verla desde otro punto de vista. La belleza plástica de las tintas blancas y negras nos sustrae de la realidad del tema, bien cifrado, muy difícil de interpretar si no fuese por su correlato en otras pinturas ${ }^{51}$.

Lo mismo sucede con las tituladas Paisaje fluvial $1^{52}$ y Paisaje fluvial I/53. En la primera, un río recorre el cuerpo de tierra, los colores dorado y celeste de cada uno refuerzan su identidad y establecen claves plásticas determinantes cuando dicho río se refleja en el negro horizonte, del que sale una masa orgánica dorada como aquél, yuxtapuesta y recortada sobre la base. Los términos avanzan los posibles significados, sin embargo, aún no tenemos datos suficientes para establecerlos. La segunda de las dos obras citadas es un dibujo en blanco y negro, con la salvedad del cauce seco del río, señalado y destacado en tal tesitura de ese modo. En las dos aparecen las masas orgánicas pesadas y con grandes huecos circulares sobre fondos neutros en sustitución del celaje.

\footnotetext{
48. Gadamer, La actualidad de lo bello, 84-90.

49. Ortega Bru y Pérez Girón, Memorias, 21-25.

50. Colección de los herederos de Ortega Bru. ALT 179.

51. Ortega Bru y Pérez Girón, Memorias, 23-25.

52. Colección de las hermanas de Ortega Bru. Técnica mixta. ALT 181.

53. Colección de los herederos de Ortega Bru. Tinta negra sobre papel fotográfico sobre tabla de aglomerado, $29 \times 19,5 \mathrm{~cm}$. APS 2, 57; ALT 182.
} 
Es muy evidente que no son paisajes naturales, ni siquiera recreaciones de tales, son representaciones fantásticas, configuraciones inventadas por Luis Ortega Bru y cargadas de simbología. Pueden entenderse como espacios y como valores específicos de los elementos que las componen, cuya posible representación genérica responde a conceptos predeterminados y estados de ánimos a los que podemos acercarnos con la interpretación de otros análogos en pinturas en las que es posible hacerlo.

Una de ellas es Paisaje de guerra ${ }^{54}$, en la que vemos elementos con un significado claro que también aparecen en las tituladas El lago, La contemplación de lo infinito y La huida. El título ya es suficientemente explícito, son paisajes de guerra, esto es, no porciones determinadas de terrenos físicos, sino porciones psíquicas del recuerdo del conflicto bélico del

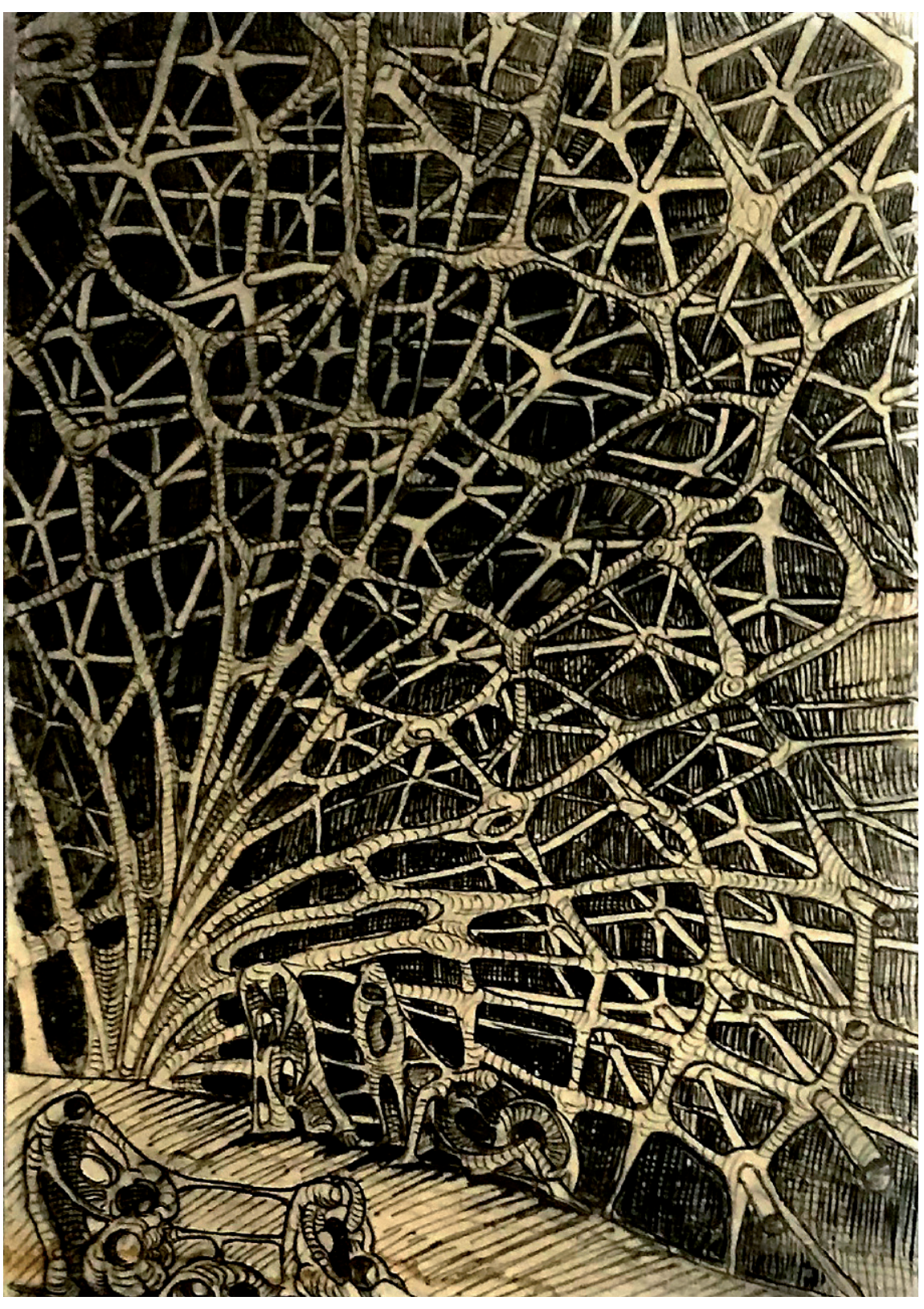

Fig. 3. Luis Ortega Bru, Paisaje de guerra, 1960-1965. año 1936, el único que él había vivido y aún lo atormentaba. El cuerpo de tierra, muy reducido, presenta en el ángulo inferior derecho una figura que pasa desapercibida por su condición de abstracción orgánica, afín a la de la masa semicircular fosilizada y calada, muy parecida a la de la Catedral II. Fijémonos bien, es el paisaje desolado después de una guerra, en el que el horror ha dado paso a algo peor que la nada, al daño reflejado por esta, recordado permanentemente por el eco que produce en la conciencia. Ese daño afecta también y sobre todo al hombre, de ahí el personaje fosilizado, anulado, carente de vida, que lo ha perdido todo en esa guerra ${ }^{55}$. El cielo oscuro confirma el estado de dolor, los temores y la angustia, en

54. Colección de los herederos de Ortega Bru. ALT 184.

55. Ortega Bru y Pérez Girón, Memorias, 21-23. 


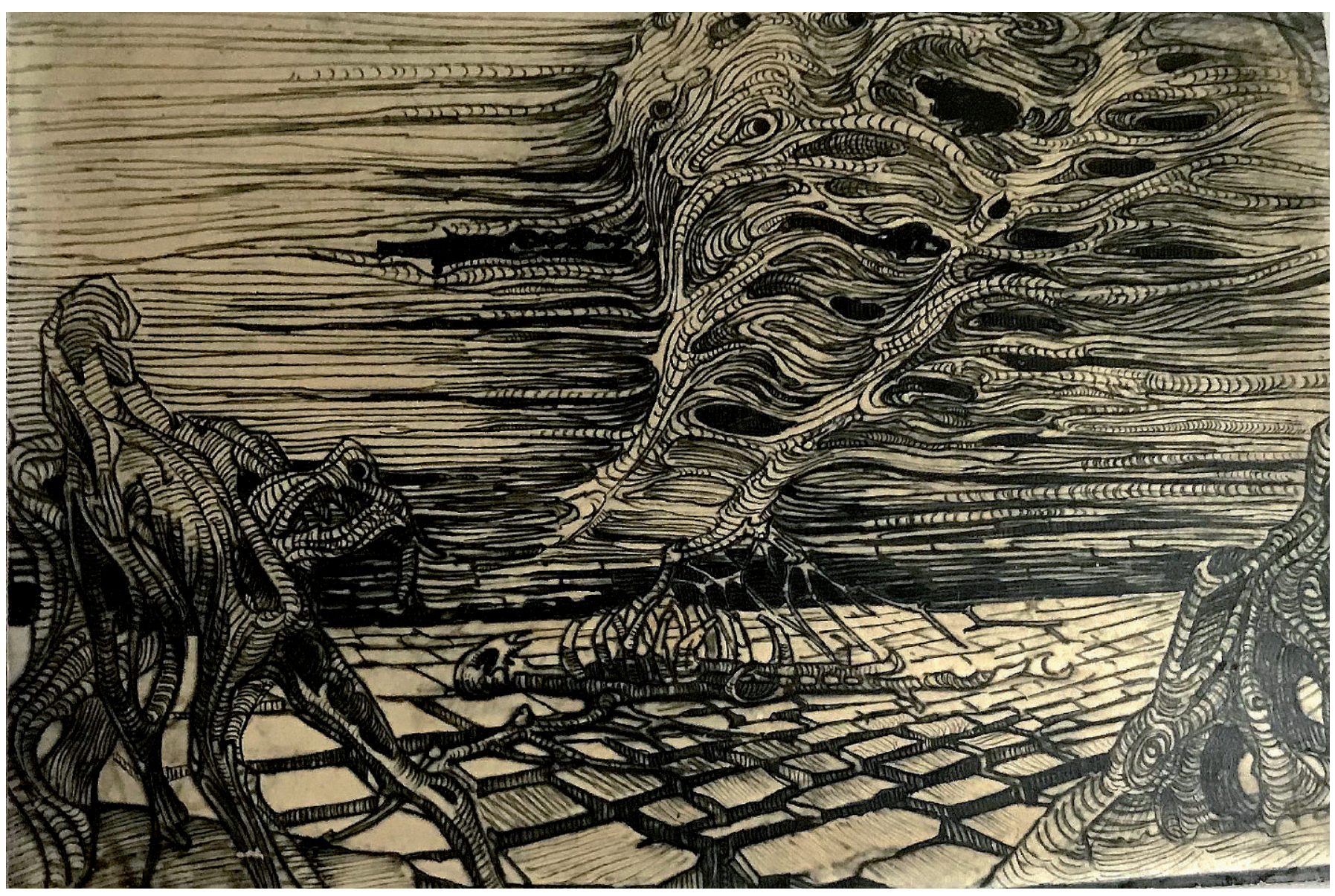

Fig. 4. Luis Ortega Bru, La huida, 1960-1965.

definitiva la rabia contenida que le habían acompañado siempre y aún tenía y no olvidaría nunca, porque es imposible olvidar ni perdonar el asesinato de una madre y la condena y la muerte violenta de un padre, y además el atropello no aclarado y en ese contexto de un hermano con solo catorce años, representados en las tres figuras fosilizadas de la parte trasera.

La inventiva fantástica fue ideal para la expresión de la psicología atormentada de Luis Ortega Bru, sin que la representación de acciones le crease problemas con la censura. Tenía motivos para temerla, aunque esas pinturas permaneciesen en un ámbito privado. Insistió en ello en La huida ${ }^{56}$, una técnica mixta resuelta en blanco y negro, en la que pueden verse elementos comunes con El lago y La contemplación de lo infinito. Entre el cuerpo de tierra y el paisaje de fondo cruzan tres diagonales con raíces y en la misma dirección, tantas como familiares directos muertos en trágicas circunstancias en la Guerra Civil. Casualidad o no, una vez más los elementos coinciden con sus circunstancias familiares. Una abstracción orgánica con forma humana camina en sentido contrario. No hay ningún dato para identificarla, eso sí, la abstracción de un hombre, que podría ser una alegoría del mismo artista, es en todo caso el ser humano genérico, cualquier persona obligada a dejar atrás su pasado. No alude a quién o cómo se produce el mal escenifi- 
cado en las formas fosilizadas que se desplazan hacia otra dimensión, sino al hecho que angustia al hombre, sea genérico, o él mismo. De ese modo, puede interpretarse como los temores y las preocupaciones del propio artista, que se manifiestan en claves fantásticas difíciles de interpretar para quien no esté bien informado de su angustioso pasado.

La preocupación o la atracción de Luis Ortega Bru hacia la muerte se manifiesta en La barca de Caronte ${ }^{57}$. El espacio del lago con la barca es breve, pues la escena está ocupada por una masa informal a modo de eje abstracto difícil de descifrar, y la proyección del propio fondo, cuyas ramificaciones orgánicas, con apariencia petrificada, forman leves diagonales que ocultan y desvelan la escena. Estos dos niveles asumen el protagonismo de la configuración, que se manifiesta como abstracta hasta que reparamos en la presencia, secundaria, de la pequeña barca.

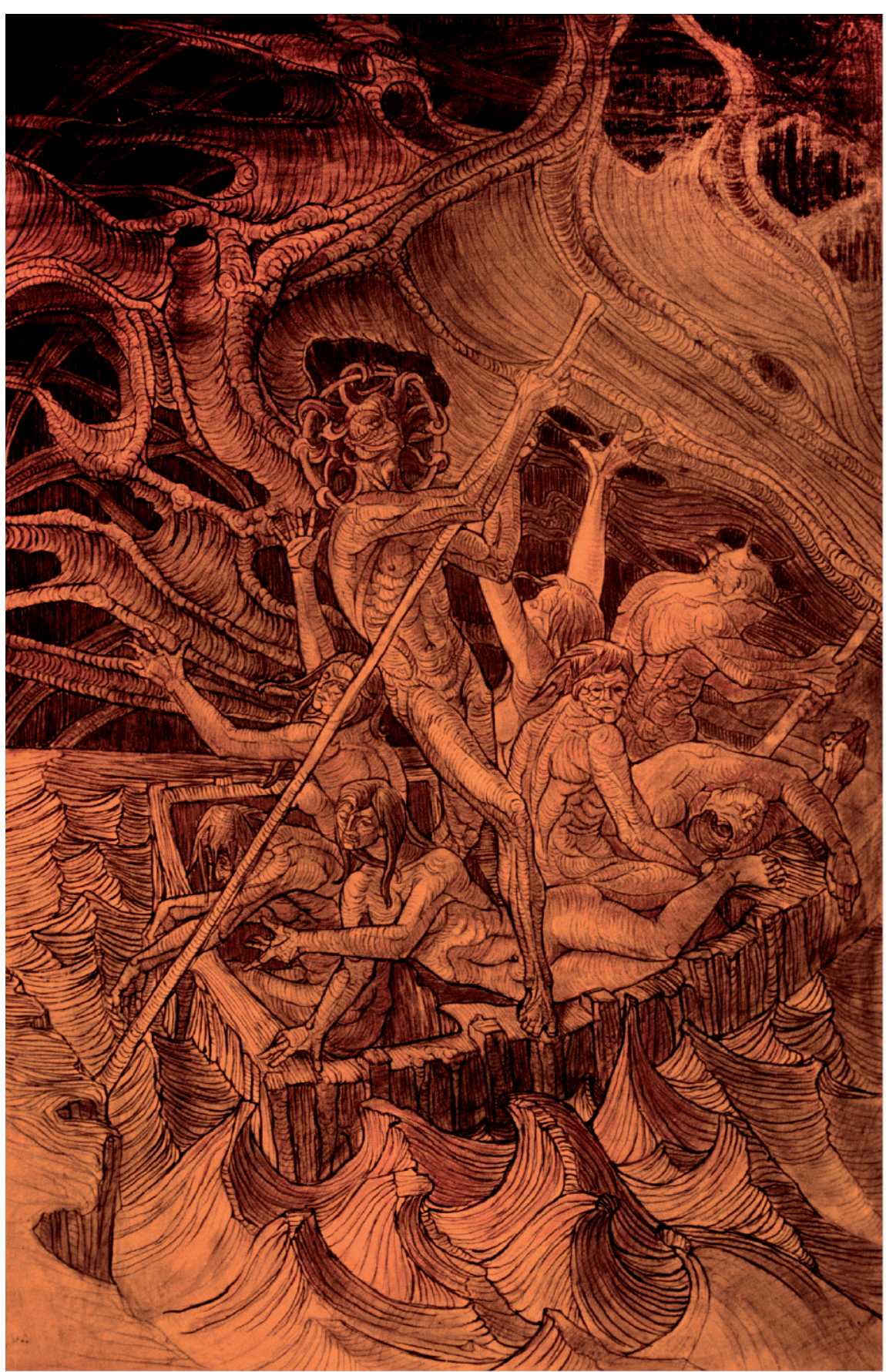

Fig. 5. Luis Ortega Bru, La barca de Caronte, 1960-1965.

Otra preocupación de Luis Ortega Bru fue el tránsito hacia la otra vida y lo efímero de esta. Era otro modo de manifestar su angustia ante lo ocurrido y lo hizo en varias ocasiones. En dos de ellas, en concreto en la La barca de Caronte $\|^{58}$ y La barca de Caronte $\mid /{ }^{59}$, el tema principal aparece en primer plano, con la única diferencia de los colores utilizados, blanco y negro en la primera, ocre y negro en esta, diferencia que no afecta a los contenidos. En ambos casos, la escena adquiere tintes fantásticos.

57. Colección Carmen Ortega León. Grafito, tinta negra y témpera blanca sobre papel grueso, $68 \times 46,5 \mathrm{~cm}$. APS 2, 61; ALT 180 .

58. Colección Carmen Ortega León. Tinta negra, grafito y carboncillo sobre papel grueso, 87 x 52 cm. APS 2, 58 ; ALT 188 .

59. Colección Carmen Ortega León. Témpera, tinta negra y grafito sobre tabla, 89 × 57,5 cm. APS 3, 20; ALT 190 . 


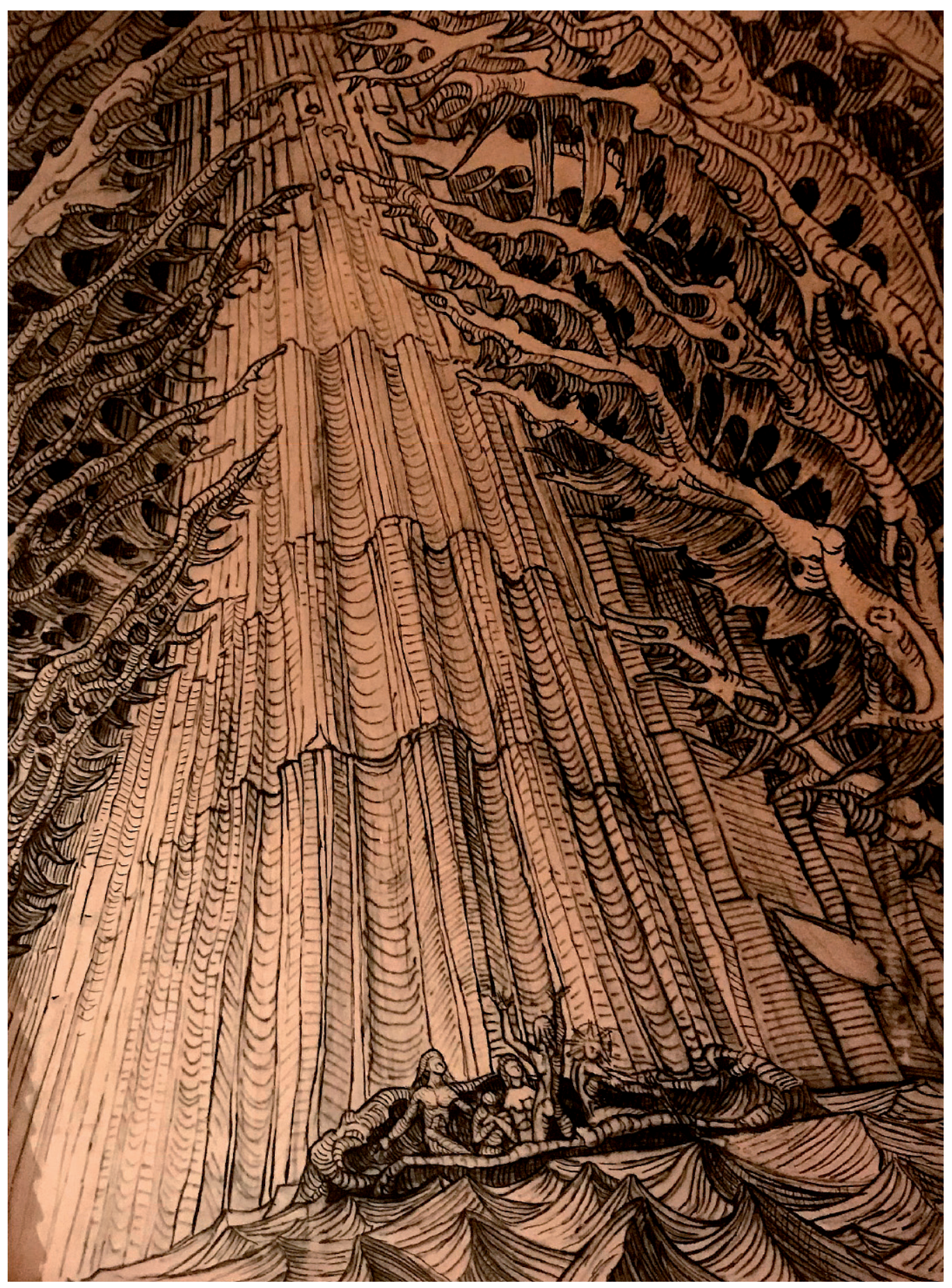

Fig. 6. Luis Ortega Bru, Caronte, 1960-1965.

Caronte transporta en su barca a seis difuntos, y presenta una figura erguida y movida sobre su eje que recuerda a los modelos escultóricos expresionistas del propio artista. Todos los elementos del cuerpo de tierra, incluida el agua, aparecen petrificados, fosilizados, mientras que el fondo está formado por una masa abstracta orgánica calada, que atraviesa en atrevida diagonal sobre el fondo negro, somero y grave. Los gestos de todos los pasajeros expresan desesperación mientras luchan con el oleaje, rígido, como si fuese una cresta dura en la que se hace casi imposible progresar. 
Con estos se relaciona la representación de Caronte ${ }^{60}$, rostro grave que alude a la misma muerte. Es una cabeza masculina de perfil y demacrada, más que la de un simple mendigo, plateada con un realismo crudo e intenso. Las grandes hebras del pelo anticipan el carácter fósil de la masa orgánica calada de fondo, estableciendo una correspondencia con la muerte que podemos hacer extensible a todas estas pinturas. El propio artista dejó un dibujo realizado con tinta azul fijado sobre la misma tabla, con otra interpretación de la cara del mismo personaje en primer plano y semifrontal.

El sentido alegórico de Soledad sonora $\left.\right|^{61} y$ Soledad sonora $1{ }^{62}$ está determinado por la representación de un hombre desnudo, en la primera con una postura muy significativa, enroscado sobre sí mismo, con los brazos sobre la cabeza y esta vuelta hacia el pecho, aislado de cuanto pasa a su alrededor. Lo hace sobre una base de tierra firme y delante de una extensión indefinida de agua y dos configuraciones abstractas y orgánicas. Es una representación lineal y esquemática, con anatomía muy detallada y fuerte musculatura que, no obstante, está supeditada a la fuerza de esas abstracciones orgánicas, una de ellas desdoblada e invertida con su reflejo en el agua; la otra suspendida y horizontal, apoyada fuera del encuadre. Su peso visual y lo incierto de esos puntos de apoyo aportan una sensación de agobio, pues parece que en cualquier momento pudiera caer y aplastarlo. La segunda versión tiene algunas diferencias, el hombre está sentado en posición semifrontal, en actitud reflexiva parecida a la de un pensador ante un paisaje escalonado, agrietado y desolado, con el agua muy lejana y bajo un árbol seco que se confunde con la masa abstracta orgánica y calada que atraviesa el fondo. Esta es la voz de la conciencia a la que también alude en El Eco.

La angustia existencial de Luis Ortega Bru tiene continuidad en La contemplación de lo infinito ${ }^{63}$, una pintura con una composición compleja que suele pasar desapercibida, pues por sus características los espectadores no suelen percibir la fuerte presencia de la figura que le da sentido, ajustada al margen derecho en la parte superior, casi fuera de la composición. Si se mira con detenimiento se identifica el busto de espaldas de un hombre, apenas girado unos grados, los suficientes para mostrarnos el inicio del ojo izquierdo y el final de la nariz. Sus rasgos lo delatan, son similares a los que dispuso en las representaciones de Caronte, incluido el pelo lacio y caído, carente de vida, que

60. Colección Carmen Ortega León. Tinta negra sobre papel sobre tabla de aglomerado, 16 × 12,5 cm. APS 2, 53; ALT 189 .

61. Colección Carmen Ortega León. Témpera y acuarela sobre papel sobre tabla, 40 × 30,5 cm. APS 3, 15; ALT 186 .

62. Colección Débora Ortega León. Témpera y tinta negra sobre tabla, 51 x $91 \mathrm{~cm}$. APS 3, 16; ALT 187.

63. Colección de los herederos de Ortega Bru. BRG Pág. 86, Lám. 145; ALT 185. 
adquiere el rango de motivo iconográfico. Así, semioculto, acecha al hombre que contempla lo infinito.

El desnudo masculino de esta alegoría comparte la iconografía de las dos versiones de Soledad Sonora, con la variante del torso erguido sobre las piernas flexionadas. La postura con una sola rodilla en tierra es muy inestable, situación acentuada por el expresionismo de la anatomía. La configuración del espacio es fundamental para la interpretación de los contenidos. La línea de tierra está en un nivel intermedio, elevada sobre un paisaje fugado en perspectiva caballera en la diagonal inferior y por debajo del horizonte abstracto superior. Con esa posición queda en condiciones de contemplar, de ver, pensar y comprender lo que la propia naturaleza le ofrece. El horizonte fugado en la parte superior está atravesado en diagonal por una masa abstracta orgánica, y entre esta y el hombre se interpone de nuevo la proyección semicircular que alude al eco, que ya hemos interpretado como la voz de la conciencia, y se pierde en la lejanía. Las líneas negras remarcan los detalles y le aportan gravedad a la representación, procedimiento en el que pudieran detectarse ciertas concomitancias con las técnicas mixtas de Salvador Dalí posteriores a 1948. Pudiera ser una representación de él mismo ante sus duras circunstancias o una genérica de cualquiera que estuviese en la misma situación; y también una alegoría del valor de la vida o la vida perdida por los suyos ${ }^{64}$. El eco que lo recuerda no tiene ni principio ni fin, como la codicia y la maldad del hombre que sigue acechándolo.

Esas preocupaciones íntimas reaparecen en Apocalipsis $1^{65}$ y Apocalipsis $/{ }^{66}$, técnicas mixtas en las que Luis Ortega Bru mostró una vez más su fuerte carácter. Los jinetes son figuras fantásticas y con un fuerte sentido expresionista, que, de modo curioso, están colocados con una superposición por proximidad que deriva de las composiciones clásicas del Partenón de Atenas. Con esa disposición los situó en un primer plano con el que minimizó la línea de tierra y el fondo. El segundo se funde con la masa orgánica circular con la que alude al recuerdo de lo que pasó unos años antes. En este caso, el eco como voz de la conciencia no solo afecta al hombre genérico, al que sufre por las miserias humanas, sino incluso a los jinetes apocalípticos, representación vehemente de la muerte misma y de la maldad del ser humano que puede producirla de modo violento. Los caballos y los jinetes se presentan como fósiles orgánicos próximos a la abstracción y no como representaciones reales, aterradoras por las desconcertantes configuraciones de los cuerpos, en todo caso inhumanos en sí mismos y en cuanto a los

64. Ortega Bru y Pérez Girón, Memorias, 19-23.

65. Colección Débora Ortega León. Técnica mixta con témpera, tinta negra y collage de papel de periódico. ALT 191.

66. Colección Carmen Ortega León. Témpera y tinta negra sobre tabla, 68,5 x 46 cm. APS 3, 19; ALT 192. 
movimientos impulsivos y las acciones que emprenden a toda velocidad. Tanto que la guadaña que porta el que está en medio, por muy afilada e hiriente que sea, no produce tanto temor como las grandes oquedades de los cuerpos, descompuestos, corroídos, amenazantes. Del mismo modo lo hace el rostro de Cabeza orgánica ${ }^{67}$, probable estudio para estos personajes.

Otras obras fantásticas de Luis Ortega Bru representaron esas preocupaciones sin el tormento psicológico de las anteriores, en un nivel simbólico muy elaborado y en relación con otras realidades que pudieran contemplarlos sin despertar sospechas sobre la verdadera carga de sentido y el propósito de la representación.

Una muy interesante es la titulada Madre e hijo ${ }^{68}$, en la que un busto femenino ocupa el primer plano. La estilización de la bella joven, con un cuello largo y muy femenino; la definición del óvalo facial, con la barbilla señalada, la boca pequeña, la nariz proporcionada respecto de esta, los ojos muy expresivos y la frente despejada; y la configuración del pelo, muy abultado y plástico, derivan de la imagen de la Inmaculada Concepción que talló para la localidad de La Línea de la Concepción, en 1954. Desde el punto de vista técnico, la definición de los volúmenes y el tratamiento de las superficies con trazos dobles de tinta y témpera, producen efectos vibrantes similares a los de las gubias sobre las superficies de madera; mientras que los toques de témpera blanca sobre la témpera gris y las precisas acotaciones lineales de la tinta negra le proporcionan caracteres pictóricos propios.

Con ser todo ello novedoso y muy representativo de una personalidad artística muy acusada, en Madre e hijo no deja de sorprender la transformación de la materia en la cabeza, por su audacia y un cierto carácter experimental avanzado, además de por la profundidad de los significados asociados. El pelo adquiere una rigidez cercana a la abstracción, confirmada por las espinas que lo fijan al cuello, la cara y la frente, con cuanto esto significa en la tradición cristiana; los ojos muestran en el interior de las pupilas bandas verticales próximas a la petrificación, en consonancia con las espinas, negando la visión natural; y la cabeza, abierta en la parte superior, presenta el interior del cráneo, sin cerebro, ocupado por un feto infantil. La uniformidad del fondo somero, sometido al mismo proceso, lo integra. El carácter fantástico de la pintura no anula la extrema belleza de la mujer y de la alegoría que representa, al atribuirle a esta una con-

67. Colección de los herederos de Ortega Bru. ALT 195.

68. Colección de los herederos de Ortega Bru. Tinta negra y tempera sobre papel. ALT 193. 
dición intelectiva superior con la que la nueva vida podrá superar los inconvenientes e incluso el mal en un sentido amplio69.

La admiración por la madre y a esta como portadora de un sufrimiento ajeno y de cualidades intelectivas transmitidas en el tiempo, tienen correlato en la dualidad de Padre e hijo ${ }^{70}$, en la que representó dos figuras itinerantes relacionadas con las esculturas masculinas de esos mismos años. Los dos personajes tienen cuerpos muy estilizados, alargados hasta la superación de las proporciones propias de la escala humana, en los que integró codificaciones y detalles realistas con un sentido plástico innato. La representación en negativo de los pliegues de los ropajes confirma esa relación con sus trabajos escultóricos y, con ello, los aprovechamientos cubistas esquematizados y llevados al límite. La seguridad de los trazos lineales con tinta negra, la témpera gris que unifica los volúmenes y los espacios y la blanca para los toques que matizan los volúmenes, aporta las soluciones pictóricas necesarias para la interpretación en el plano. Las dos figuras transitan un camino con suelo firme formado por losas de piedras regulares, flanqueado por dos hileras de árboles que se transforman en grandes pilares orgánicos y lo cubren. La vibración y la confluencia de esos árboles rígidos con su grado de abstracción generan el contexto fantástico, irreal, sobre todo por los cortes en los troncos de los más cercanos, con la apariencia de bocas abiertas hablándoles. El padre se ofrece como guía del niño, todavía dependiente, necesitado de la figura paterna, imprescindible, pese a lo que digan los demás. La concordancia técnica con la anterior es elevada, y las diferencias compositivas también; tanto como las equivalencias formales y el trasfondo de los significados.

\section{No podía olvidarlo, a vueltas con el éxodo a partir de 1965}

En esos años realizó sus últimas pinturas fantásticas, en 1965-1966; dos nuevas series de paisajes urbanos y paisajes rurales, en 1965-1969; los temas deportivos, entre 1965 y 1970; y lo que se tuvo como un homenaje a los grandes maestros de las vanguardias históricas, en 1969-1970, que, en realidad, recogía de modo claro y directo su tremenda frustración por el éxodo que un día ya lejano sufrió y este momento comparaba al mismísimo del pueblo de Gibraltar cuando se tuvo que asentar en lo que después fue San

69. Luque Teruel, Luis Ortega Bru. Vanguardia, 246-247.

70. Colección de los herederos de Ortega Bru. Tinta negra y tempera sobre papel. ALT 194. 


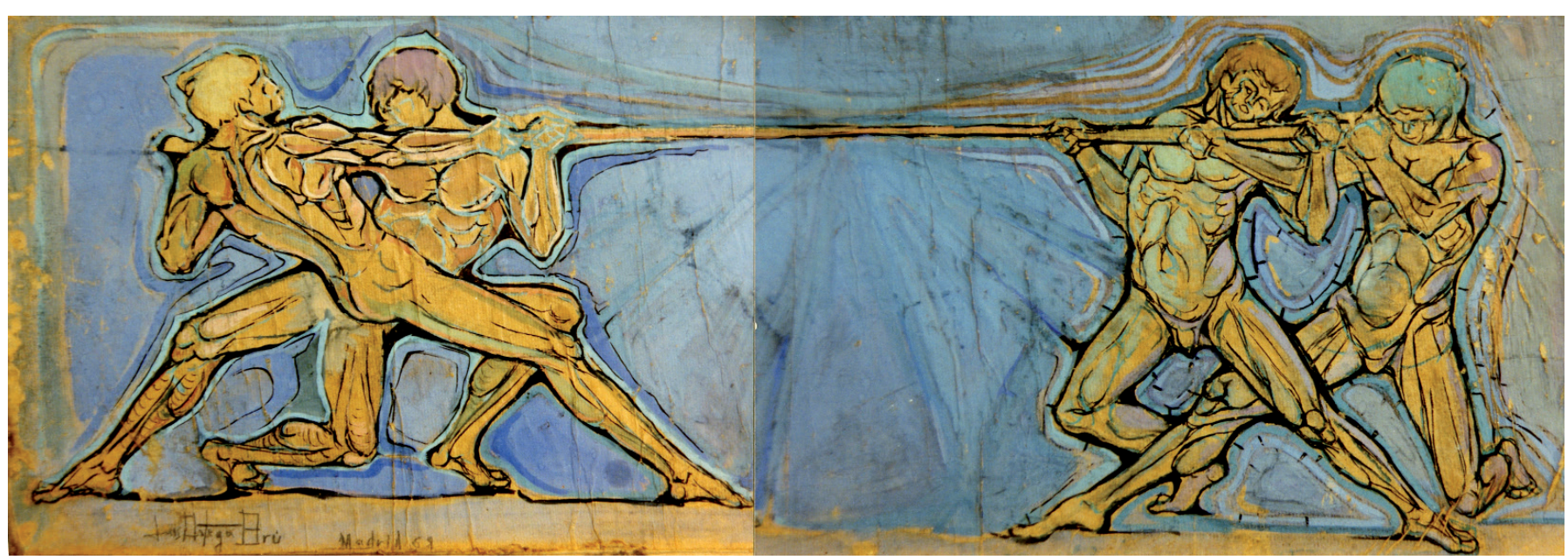

Fig. 7. Luis Ortega Bru, La fuerza, 1965-1969.

Roque. En todos los casos encontró el motivo para introducir sus reivindicaciones o censura oculta de lo que había pasado.

Entre las primeras La barca de Caronte $\mid I^{171}$, en fecha próxima a 1965. El tema es el mismo de las pinturas fantásticas analizadas en el capítulo anterior, ahora con técnicas mixtas análogas a las deportivas de estos mismos años. La composición es la misma de La barca de Caronte $I^{72}$ y La barca de Caronte $1{ }^{73}$; sin embargo, y según lo apuntado, la ejecución varía debido a las distintas posibilidades y cualidades de cada procedimiento. Las temperas de color y la base azul para los espacios, y ocres y amarillos para las masas musculares y los contrastes lumínicos, y los trazos de tinta negra para reforzar los perfiles, determinan configuraciones con una definición distinta, aunque también con deformaciones, codificaciones y esquematizaciones que las apartan de los modelos naturales. Las abstracciones orgánicas de las cabezas y los rostros están en consonancia con la transformación del paisaje de fondo y permiten establecer la continuidad en la carga de sentido.

En esa dinámica están los dibujos, Soledad74, en el que interpretó un desnudo realista e indeterminado en posición fetal sobre un fondo abstracto formado por ondas irregulares que aluden a un elemento orgánico desmaterializado, con lo que, con la disposición iconográfica y la simbología reconocible, quedan asociadas las ideas de la vida y la muerte $y$, en segunda instancia, expuesta la idea de la procedencia de la vida; y Desnudo femenino ${ }^{75}$, con un desnudo en pie y parcialmente cubierto por las ondas en sentido vertical,

71. Colección Manuel González Scott. ALT 315.

75. Colección Carmen Ortega León. Tinta negra sobre papel sobre tabla de aglomerado, $25 \times 12$ cm. APS 2, 56; ALT 249. 


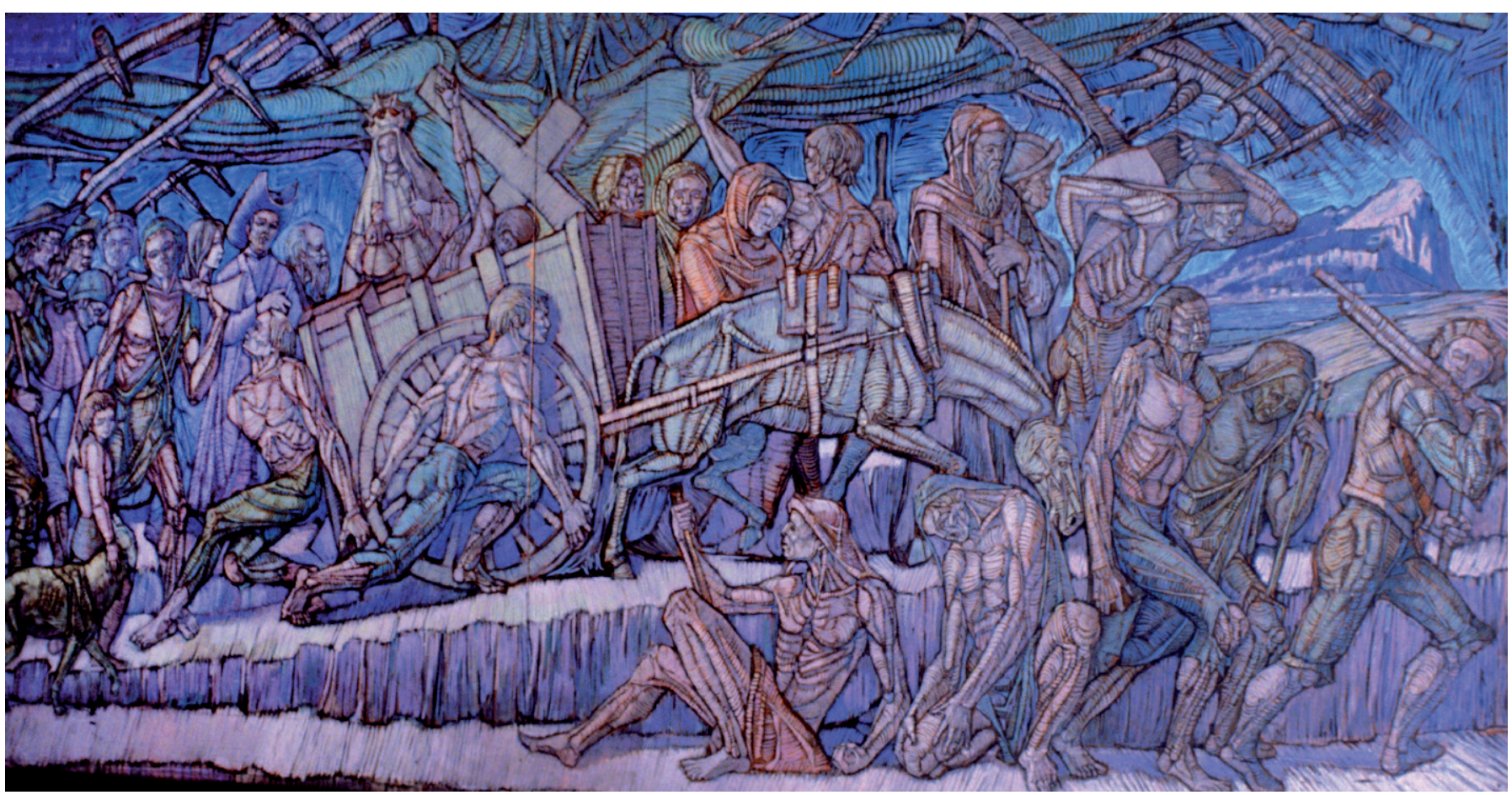

Fig. 8. Luis Ortega Bru, Éxodo, 1970.

cuyo potente claroscuro provoca un efecto fosilizado análogo. Ambos hay que fecharlos en torno a 1965.

A partir de esa fecha, Luis Ortega Bru dio un giro radical a su pintura, y optó por planteamientos expresionistas radicales en el posicionamiento conceptual y el aprovechamiento de los recursos plásticos, con tendencia a la simplificación de los volúmenes y las deformaciones por medio de los colores puros, brillantes e intensos. Lo hizo en tres grandes grupos en los que el trasfondo de la Guerra Civil tiene una incidencia desigual, difícil de percibir en los paisajes urbanos del medio rural y los paisajes rurales; muy directa y evidente en la representación de la muerte, el dolor y el éxodo, en el que aparenta ser un homenaje a los grandes maestros de las vanguardias históricas, sobre todo Picasso y Joan Miró.

Las codificaciones están presentes en todos los paisajes urbanos de este momento, si fuese solo en varios pudiéramos pensar en una suposición más o menos aventurada, en simples hipótesis interpretativas; sin embargo, se dan en todas las pinturas y eso ya no puede ser causalidad y mucho menos un exceso de celo interpretativo del historiador del arte. Los significados de las distintas codificaciones encajan cuando vamos descifrándolos. Cuando todos pensaban que Luis Ortega Bru había olvidado su pasado para siempre, él lo reflejaba una y otra vez en estas configuraciones, pasando desapercibidas sus constantes denuncias bajo la apariencia de lo que para muchos solo eran 
extravagancias vanguardistas. Cada paisaje era una denuncia concreta, un grito desgarrado contra los causantes de su inmenso sufrimiento.

Con esos paisajes pueden formarse tres grupos, los del tercero muestran el trasfondo que aquí estudiamos de un modo mucho más claro, la mayoría de las veces con una evidencia descarnada, grave, propiciada por el paso de los años, y el desgaste progresivo de la dictadura ${ }^{76}$. Benito Rodríguez Gatius consideró que Personaje Triple $e^{77}$ es una pintura surrealista influencia por Picasso ${ }^{78}$, comenzaba así a desviarse la atención hacia los grandes maestros, con los que pudieran relacionarse los temas que en realidad respondían a vivencias propias y no a préstamos plásticos de otros artistas. Una figura plana y lineal es muy esquemática y está vestida al modo de los togados romanos, con la particularidad de tener tres caras en una sola cabeza, de manera que cada lado de una de las caras lo es también de la siguiente. La postura de las manos, sosteniendo y cubriendo un recipiente, recuerda la de los sacerdotes en la comunión; con lo que concuerda la indumentaria, asimilable a la de los oficiantes paleocristianos. Lo delata la estructura esquemática situada detrás, abierta hacia ambos lados como dos grandes alas, a modo de los ángeles de una escolta celestial. Si lo vemos con amplitud de miras, no son pocos los dioses pre cristianos con tres cabezas, sobre todo en la antigua iberia; y tampoco los grandes sillones alados, de procedencia mesopotámica, asumida aquí a través de los colonos fenicios. Con la misma amplitud de miras tampoco debería descartarse que pudiera ser una representación sagrada, una alegoría del carácter triple del gran misterio católico. Lo único que la relaciona con Picasso son los planos y los elementos frontales de estirpe cubista de los tres rostros, en una misma línea central de visión. Con independencia de esto, en la pintura de Luis Ortega Bru hay una intencionalidad que la distingue también de los Triplex de Luis Gordillo ${ }^{79}$, con los que comparte la multiplicación de la unidad formal y el desdoblamiento de una misma figura, y difiere por completo en el desarrollo formal y ese contenido simbólico.

El interés autobiográfico es extraordinario en La huida de Málaga ${ }^{80}$, de la que Benito Rodríguez Gatius dijo que los cuatro personajes, dos mujeres, un hombre y un niño, son "seres metamorfoseados por la crueldad picassiana" ${ }^{\text {"1 }}$. Las referencias de Picasso

\footnotetext{
76. Luque Teruel, Luis Ortega Bru. Vanguardia, 310-312.

77. Herederos de Ortega Bru. RG 87, Lám. 147; ALT 343.

78. Rodríguez Gatius, Ortega Bru, 87.

79. Francisco Calvo Serraller, Luis Gordillo (Madrid: De León Editores), 104-107; Dan Camerón, Luis Gordillo. Los años ochenta (Madrid: Tabapress, 1991), 19-21.

80. Herederos de Ortega Bru. RG 86, Lám. 146; ALT 358.

81. Benito Rodríguez Gatius, Ortega Bru, 86.
} 
son muy claras, tanto como que si nos quedamos solo en ellas estaremos falseando el contenido simbólico y la carga de sentido de la pintura, pues lo que Luis Ortega Bru representó fue la salida de su familia de la casa propia en la calle Málaga de San Roque, hecho que tuvo que causarle un fuerte impacto en su juventud.

El planteamiento genérico y las potentes deformaciones de los personajes de La huida de Málaga ante la dramática situación no dejan lugar a dudas en cuanto al tremendo sufrimiento de Luis Ortega Bru en su día, y el que en ese momento tan avanzado de su vida aún lo desgarraba psicológicamente. Veamos con detenimiento la pintura, la primera mujer está representada de modo frontal y sin rostro en el lado izquierdo del soporte. Es una figura encogida, afligida. La cara ha sido sustituida por una abstracción deforme de los volúmenes generales de toda la cabeza, en la que los planos de ascendencia cubista y las proyecciones informales se mezclan y anulan entre sí. Esa mujer se distingue por los voluminosos pechos, atributos claros de su condición femenina y desde época remota de la maternidad en sí, significados virtuales que predominan sobre la abstracción debida a las deformaciones de la superficie amarilla con la que representó la estrecha falda. La siguiente mujer está de perfil y vuelta hacia el lado contrario, dándole la espalda a la primera, posicionamiento muy significativo. Su figura está más simplificada aún, tanto que la cabeza, disminuida y desdoblada por un juego de luces y sombras, no recuerda en nada a la de una persona. Camina en otra dirección y protege a un niño, deformado y con aprovechamientos cubistas. Un hombre con los brazos abiertos se dirige a ellos, es una silueta plana en la que revierten características de las tres anteriores. El fuerte contraste de las expresivas y dramáticas sombras que se recortan sobre el fondo somero duplica la escena y nos reafirma en la realidad expresionista de su obra y el hecho que narra, la pérdida de una madre, la separación de la familia y su encuentro con esta.

La ascendencia de las formas y el espíritu de Picasso es más notoria en Huida de Málaga. Madre con su hijo muerto ${ }^{82}$, claro que el tema es en sí mismo heredero del cruel sufrimiento de miles de madres y abuelas españolas en la Guerra Civil. La iconografía y la libre utilización de los recursos y los medios expresivos para la configuración de los cuerpos, derivan de aquél; los colores no, pues Luis Ortega Bru optó por un fondo rojo somero encendido y rosas fuertes para los cuerpos que, junto a los azules de la falda y la aplicación de los mismos mediante manchas yuxtapuestas, dieron un resultado final muy distinto. La ascendencia de Picasso en cuestiones plásticas, que no se dis-

82. Colección Carmen Ortega León. Témpera e hilos sobre cartulina roja, 50,5 x 35 cm. APS 3, 1; ALT 359 . 
cute aquí, hay que matizarla y entenderla en el reconocimiento de la miseria humana y los dramas de la humanidad, pues la representación es en realidad un icono virtual y universal del sufrimiento de las madres que pierden un hijo en conflictos armados o de modo violento. Las dos cuestiones son ciertas y se potencian entre sí, circunstancia que pudiera confundirnos si no tenemos en cuenta los antecedentes y quién era Luis Ortega Bru.

La ascendencia plástica de Picasso es mucho más intensa en los dibujos titulados Figura cubista ${ }^{83}$ centrado en la representación de un ensamblaje cubista, distinto a los originales de aquél por su consideración figurativa y la perfección del complejo montaje; Cabeza picassiana ${ }^{84}$, cuya configuración deriva de las trágicas y lineales del genio malagueño en los años treinta; Cabeza y composiciones abstractas ${ }^{85}$, en el que la indagación en los procesos de transformación de las formas supera el vínculo; Danza ${ }^{86}$, una composición lineal basada en la inestabilidad de las proyecciones; y Mujer corriendo ${ }^{87}$, versión de la Bañista ${ }^{88}$ que Picasso modeló con derivaciones orgánicas en Boisgeloup, en 1931, resuelta aquí con superficies planas relacionadas con algunos relieves deportivos tallados por Luis Ortega Bru a finales de los años sesenta.

La fuerte carga emocional de Luis Ortega Bru puede verse en Composición abstracta ${ }^{89}$, Composición abstracta $1{ }^{90}$ y Composición abstracta $\mathrm{V} /{ }^{91}$ en las que partió de las relaciones internas de los paisajes de finales de los años sesenta con un nuevo propósito que rechaza las referencias reales. La linealidad y las deformaciones orgánicas de Composición abstracta II/92 lo acercan una vez más a Picasso; no obstante, el color azul claro del esquema lineal y el rojo apagado de la silueta de la masa informe se igualan en un primer plano sobre las caprichosas abstracciones que llenan el espacio de un modo muy personal y nada acorde con intenciones estilísticas predeterminadas. Esto puede verse de modo muy acusado en Composición abstracta IV93, con una proyección geométrica fugada en la que no se detecta vínculo con ningún artista concreto y anticipa los plantea-

\footnotetext{
83. Colección Carmen Ortega León. Lápiz sobre papel, 14,5×23,5 cm. APS 4, 13; ALT 363.

84. Colección Carmen Ortega León. Lápiz sobre papel, 21,5 ×16 cm. APS 4, 10; ALT 360.

85. Colección Carmen Ortega León. Lápiz sobre papel, 21,5 x 16 cm. APS 4, 11; ALT 361.

86. Colección Carmen Ortega León. Lápices de colores sobre papel grueso, 14,5×23,5 cm. APS 4, 12; ALT 362.

87. Colección Carmen Ortega León. ALT 363 B.

88. Museo Picasso, París. WS 115.

89. Colección Carmen Ortega León. Témpera sobre cartulina negra, 17 x 34 cm. APS 4, 10; ALT 364.

90. Colección Carmen Ortega León. Témpera y lápices de colores sobre cartulina negra, $34 \times 17$ cm. APS 3, 12; ALT 365 .

91. Colección Carmen Ortega León. Témpera y tinta negra sobre cartulina negra, 13,5 ×31 cm. APS 3, 3; ALT 369 .

92. Colección Carmen Ortega León. Témpera sobre cartulina marrón, $29 \times 21$ cm. APS 3, 6; ALT 366 .

93. Colección Carmen Ortega León. Témpera y tinta negra sobre cartulina negra, $23 \times 29,5 \mathrm{~cm}$. APS 3, 5; ALT 367.
} 
mientos constructivistas que fundamentaron su evolución final en la siguiente década. El expresionismo del color y la fuerza expresiva lo mantienen aún en este contexto.

En otras pinturas dejó claro su conocimiento y admiración por Joan Miró. Con este se relacionan la alternancia de formas abstractas irregulares en un mismo plano y el valor de las configuraciones de cada una mediante el resalte de los colores puros, fuertes, intensos y brillantes de Composición abstracta $V^{94}$ y Composición abstracta con fieltros $^{95}$. Esta última con una base pintada y un tratamiento mixto con acabados textiles muy en consonancia con lo que Joan Miró hacía en aquel momento. En los dos casos, Luis Ortega Bru no se limitó a un ejercicio estilístico vacío, sus decisiones plásticas tienen un fuerte impacto emocional. Por ejemplo, el fondo negro de la primera y el rojo somero de la segunda sirven de pantalla a una serie de formas mucho más elaboradas, con contrastes de colores e incidencia de la luz y sin la monumental simpleza de aquél.

\section{La ciudad vacía}

Las últimas pinturas de Luis Ortega Bru, fechadas en torno a 1975, tienen como tema común la representación de ciudades vacías como espacios simbólicos en perspectiva ${ }^{96}$. El tema en sí es el espacio mismo que acoge a los núcleos urbanos y la proyección en perspectiva de los mismos. Por ello, no aparecen lugares concretos y mucho menos acciones determinadas o personas o seres vivos de ningún tipo. Desde un punto de vista formal pudiéramos organizarlas en dos grupos, uno con vistas aéreas en las que se identifican volúmenes concretos o núcleos urbanos simplificados y esquemáticos, reducidos a formas geométricas simples, casi abstractas; el otro con pinturas en las que las estructuras tubulares o lineales de los primeros planos indican la fuga que determina un espacio amplio, indefinido e infinito o intermedio respecto de las estructuras arquitectónicas proyectadas debajo, sobre o detrás.

Las pinturas del primer grupo tienen tonalidades ocres, verdes y grises muy uniformes y aumentan los efectos indicados, fomentando la valoración prioritaria del espacio, perceptible en la distancia establecida entre el ojo del espectador y las estructuras fugadas. La importancia del vacío es fundamental, tanto que si se le da la vuelta a una

94. Colección Carmen Ortega León. Acuarela, lápices de colores y tinta negra sobre cartón, 33 x 50,5 cm. APS 3, 4; ALT 368 .

95. Colección Carmen Ortega León. Fieltros pegados sobre cartulina roja, 50,5 x 35 cm. APS 3, 2; ALT 370.

96. Luque Teruel, Luis Ortega Bru. Vanguardia, 348-351. 
de estas pinturas sigue determinante; aunque con ello se pierda el orden lógico de los volúmenes y de la dinámica visual. El vacío, la nada invisible, mantiene la consistencia y no sufre alteración ninguna.

Con ellos se relaciona el dibujo Cukiloski Troskiski97, cuyo título implica un contenido simbólico de orden político y social. Luis Ortega Bru reclamó con ello por primera vez de modo directo unos principios políticos. Una propuesta parecida es la de Estudio de perspectiva. Cubo ${ }^{98}$, en 1975, sobre las cuatro caras de un pequeño cubo de madera, en las que la proyección continua pide una posición angular para la correcta apreciación de los distintos sentidos de la fuga, y las perspectivas decrecientes no necesitan la nitidez pictórica de las anteriores, por lo que los tonos pasteles y la progresiva disminución y pérdida del color se sustentan en el valor de las líneas.

En otros como Composición abstracta, Perspectiva ${ }^{99}$, y La esfera ${ }^{100}$ el espacio es interior y los volúmenes que lo acotan se distancian como si fuesen elementos suspendidos en el espacio. Ese sistema compositivo lo aplicó a Rostro en perspectiva ${ }^{101}$, pintura figurativa en la que los planos verticales de la estructura previa sostienen los ojos y la nariz de un hombre, tal vez su propia mirada. La que proyectó sobre el peñón de Gibraltar como símbolo de San Roque cuando pintó el cartel de la candidatura independiente para las elecciones municipales del año 1980, enmarcado por las banderas de Andalucía y España en dos de sus lados y formando ángulo, como símbolo de superación y nuevo futuro ${ }^{102}$.

\section{Conclusiones}

La pintura fue una actividad alternativa y poco o nada conocida en su momento en la carrera artística de Luis Ortega Bru. La mayoría de esa pintura, agrupada en momentos concretos de su producción y en función de características exclusivas de cada uno de ellos, está realizada en pequeño formato y con técnicas mixtas sobre soportes como cartones, papeles y tablas. Esas circunstancias, en buena medida, debidas a la falta de

\footnotetext{
97. Colección Carmen Ortega León. Lápices de colores sobre papel, 20,5 x 13,5 cm. APS 4, 5; ALT 443.

98. Museo Ortega Bru, San Roque. ALT 448.

99. Colección Carmen Ortega León. Témpera y tinta negra sobre tabla, 73,5 × $21 \mathrm{~cm}$. APS 3, 8; ALT 453.

100. Colección de los herederos de Ortega Bru. ALT 455.

101. Colección de los herederos de Ortega Bru. ALT 196.

102. Museo Luis Ortega Bru, San Roque. ALT 580.
} 
interés profesional, al menos entendido este desde un punto de vista económico, y más aún esta última condición, le proporcionaron una gran libertad de ejecución y expresiva. El considerable número de dibujos y pinturas con técnicas mixtas o con témperas aumenta el interés de cada uno de esos grupos.

Si los diversos especialistas que han estudiado su escultura ya habían advertido un énfasis expresivo exacerbado en sus imágenes pasionistas, que pudiera interpretarse como un grito desgarrado, como una especie de pathos alimentado por la angustia, lo que bien pudiera interpretarse como la proyección y la expresión del sufrimiento de su propia vida en esas obras, en estas pinturas pudo desarrollar un sistema de equivalencias de principios existencialistas básicos y formas vanguardistas derivadas de distintas experiencias personales.

Hay que advertir que Luis Ortega Bru no conoció las vanguardias a través de planteamientos teóricos sino de conocimientos prácticos debido a su interés por las expresiones más diversas en las exposiciones que visitaba en Madrid en la década de los años cincuenta, en las que a veces accedió a un conocimiento indirecto y reelaborado de las propuestas internacionales que le llamaron la atención; y otras, las menos, de modo directo a través de los artistas que mostraban su obra en la capital.

El doble lenguaje fue muy frecuente en los años sesenta y setenta para eludir de forma eficaz la censura, no hay más recordar los códigos periodísticos del diario El Pueblo; y no digamos las canciones de Paco Ibáñez, que mediante poemas del siglo XVII expresaba entre líneas asuntos sociales vigentes en aquel momento. Se establecía así un código de comunicación cifrada, que aún alcanzó a Luis Eduardo Aute con la canción Al Alba mediada la siguiente década, un tema de amor que en realidad aludía a los últimos fusilados en la etapa final de la dictadura. No es aventurada, pues, la doble lectura de las pinturas de Luis Ortega Bru, en las que aparecen cuerpos fosilizados, sin vida, jinetes apocalípticos, barcas de Caronte y otros símbolos de la muerte y el paso a la otra vida; además de elementos como el eco que, de modo simbólico, puede perfectamente aludir a un sonido que se repite una y otra vez, que retumba hasta hacerse insoportable.

Ese doble lenguaje a través de figuras ambiguas, a veces incluso imperceptibles por su ubicación, su definición o el alcance de sus formas, aprovecha un mimetismo intuitivo y eficaz para minimizarlas en el total de la configuración, en el que adquieren protagonismo otros elementos plásticos secundarios, que las ocultan físicamente y 
dejan el doble significado simbólico en un segundo plano de atención. Por ese motivo es importante agudizar la lectura visual de cada una y del conjunto de cada grupo, pues en ambos sentidos mostró una extraordinaria unidad.

En los primeros dibujos de los años treinta y cuarenta mostró personajes escuálidos, vencidos por las circunstancias, cargados de dolor y miserias físicas. Respondían a la cruda realidad de una posguerra dramática, muy dura para todos y, especialmente, para los vencidos. Con el grupo de pinturas y esculturas de La piedra filosofal planteó el pensamiento como clave de un nuevo lenguaje, como la necesidad de proyectar un modo directo de comunicación con claves simbólicas que se resuelven de modo intelectivo. En todas, salvo en una, los volúmenes son prietos y contundentes, y sin excepciones están realizadas con témperas con colores puros e intensos, sean cálidos o fríos; e igualmente, muestran desplazamientos a través del impacto que muestran los trazos perimetrales sobre el fondo somero.

En las pinturas fantásticas de la década de los sesenta se pueden ver alusiones muy diversas a la muerte, incluso de un modo directo, como ya quedó apuntado. Unas son técnicas mixtas, con tinta negra y témpera; y otras, dibujos con el mismo tipo de tinta, en los dos casos con acabados lineales y líneas onduladas muy expresivas en contraste con diversos tipos de abstracciones y espacios vacíos. Muchas coinciden en la relación entre la vida fosilizada y la naturaleza, binomio con el que aludió al dolor contenido y la rabia que le seguían produciendo los recuerdos. Esta interpretación se apoya en una coincidencia que no puede ser casualidad, pues se repite en varias ocasiones: las figuras fosilizadas son tres y una de menor tamaño, lo que coincide con sus padres y su hermano fallecido en circunstancias dudosas en la misma época.

Ya a inicios de los años setenta comenzó a trabajar el tema del éxodo, en el que pudo volcar los amarguísimos recuerdos de cuando una vez consumada la pérdida de sus padres y hermano, los restantes hijos vieron embargados sus bienes y se vieron obligados a abandonar su casa en la calle Málaga de San Roque, y aun la propia localidad. En este caso hay que distinguir el tema del relieve de gran formato y la pintura titulados El Éxodo, del año 1970, del dibujo El éxodo de Málaga, que no puede interpretarse como una alusión a Picasso, como se ha dicho hasta el momento debido a algunas influencias formales en las pinturas de esa época, témperas expresionistas con una fuerte carga dramática, pues este no sufrió ningún éxodo ni exilio alguno, y ese era el nombre popular de 
la calle en la que Luis Ortega Bru vivía con sus padres en San Roque. Es evidente a esas alturas de su vida que los recuerdos aún lo acompañaban, que no los había olvidado.

\section{Referencias}

Calvo Serraller, Francisco. Luis Gordillo. Madrid: De León Editores, 1986.

Cameron, Dan. Luis Gordillo. Los años ochenta. Madrid: Tabapress, 1991.

Chacón Álvarez, José Antonio. Las rutas del Arte Contemporáneo en Andalucía. Sevilla: Fundación José Manuel Lara, 2004.

Gadamer, Hans-Georg. La actualidad de lo bello. Barcelona: Ediciones Paidós, 1977.

García Rossell, Carmen. "Luis Ortega Bru." En De Jerusalén a Sevilla, La Pasión de Jesús. Vol. IV, 60. Sevilla: Editorial Tartessos, 2005.

Gibson, Ian. Vida, pasión y muerte de Federico García Lorca. Madrid: Plaza \& Janet, 1998. Barcelona: Ediciones Folio-Diario ABC, 2003.

González Torres, Javier. "Mística, religiosidad y compromiso social. Actitudes frente a la vida y el Arte." En Ortega Bru. Centenario (1916-2016), editado por Javier González Torres, 81-92. Málaga: Archicofradía Sacramental de Pasión y Ars Málaga-Palacio Episcopal, 2016.

Guasch, Ana. 40 años de pintura en Sevilla (1940-1980). Sevilla: Excelentísima Diputación Provincial de Sevilla-Obra Cultural de la Caja de Ahorros Provincial San Fernando, 1981.

Luque Teruel, Andrés. "Actualidad de un amplio Catálogo." En Luis Ortega Bru. Un genio en solitario, editado por Andrés Luque Teruel, 257-401. Sevilla: Tartesos, 2011.

---. Luis Ortega Bru. Vanguardia inédita. Sevilla: Tartessos, 2011.

---. "Personalidad artística. Etapas y estilos." En Luis Ortega Bru. Un genio en solitario, editado por Andrés Luque Teruel, 56. Sevilla: Tartesos, 2011.

---. "La relación con las vanguardias como modo de expresión." En Ortega Bru. Centenario (1916-2016), editado por Javier González Torres, 53-63. Málaga: Archicofradía Sacramental de Pasión y Ars Málaga-Palacio Episcopal, 2016.

Martín Martín, Fernando. "Notas sobre la creación contemporánea en Sevilla." En Pintura de Sevilla, 1952-1992, LII. Sevilla: Comisaría de la ciudad de Sevilla para 1992 y Monte de Piedad y Caja de Ahorros de Huelva y Sevilla, 1992.

---. "Pintura contemporánea en Sevilla." En Sevilla y su Provincia. T. V, 363-404. Sevilla: Gever, 1993.

Ortega Bru, Marina, y Antonio Pérez Girón. Memorias. Luis Ortega Bru. San Roque: Fundación Municipal de San Roque, 2002.

Ortega León, Luis Ángel, Débora Ortega León, y Carmen Ortega León. Proyecto Luis Ortega Bru. Sevilla: Archivo de los hermanos Ortega León, inédito.

Parra Sevilla, Alberto. "Obra inédita de Luis Ortega Bru." Trabajo de investigación, Universidad de Sevilla, 2002.

Pérez Girón, Antonio. El San Roque de Luis Ortega Bru. San Roque: Delegación Municipal de Cultura, 2016. 
Ríos Delgado, Rafael. "El escultor Ortega Bru y la Hermandad de la Bofetá." Boletín de las Cofradías de Sevilla, no. 521 (2002): 38-39.

---. "El artista Juan Pérez Calvo." Boletín de las Cofradías de Sevilla, no. 539 (2004): 38-43.

Rodríguez Gatius, Benito. Ortega Bru. Sevilla: Guadalquivir, 1995.

---."Semblanza sobre la figura del escultor Luis Ortega Bru." Boletín de las Cofradías de Sevilla, no. 526 (2002): 49.

---. "Desafiando a la vida con el Arte." En Luis Ortega Bru. Un genio en solitario, editado por Andrés Luque Teruel, 26. Sevilla: Tartessos, 2011.

Sánchez López, Juan Antonio. "Citius, altius, fortius. Deporte, dinamismo, cuerpo." En Ortega Bru. Centenario (1916-2016), editado por Javier González Torres, 65-80. Málaga: Archicofradía Sacramental de Pasión y Ars Málaga-Palacio Episcopal, 2016.

Schurian, Walter. Arte Fantástico. Madrid: Taschen y Diario El País, 2008.

Tobaja Villegas, Manuel. "Luis Ortega Bru." En El Arte en la Semana Santa. Artistas en el recuerdo. Sevilla: Caja de Ahorros Provincial San Fernando de Sevilla, 1986. 